\title{
Osteopontin Bridging Innate and Adaptive Immunity in Autoimmune Diseases
}

\author{
Nausicaa Clemente, ${ }^{1}$ Davide Raineri, ${ }^{1}$ Giuseppe Cappellano, ${ }^{2}$ Elena Boggio, ${ }^{1}$ \\ Francesco Favero, ${ }^{1}$ Maria Felicia Soluri, ${ }^{1}$ Chiara Dianzani, ${ }^{3}$ Cristoforo Comi, ${ }^{4}$ \\ Umberto Dianzani, ${ }^{1}$ and Annalisa Chiocchetti ${ }^{1}$
}

${ }^{1}$ Department of Health Sciences and Interdisciplinary Research Center of Autoimmune Diseases (IRCAD), "A. Avogadro" University of Piemonte Orientale (UPO), Novara, Italy

${ }^{2}$ Biocenter, Division for Experimental Pathophysiology and Immunology, Laboratory of Autoimmunity, Medical University of Innsbruck, Innsbruck, Austria

${ }^{3}$ Department of Drug Science and Technology, University of Torino, Torino, Italy

${ }^{4}$ Department of Translational Medicine, Neurology Unit, "A. Avogadro” UPO, Novara, Italy

Correspondence should be addressed to Annalisa Chiocchetti; annalisa.chiocchetti@med.uniupo.it

Received 6 August 2016; Revised 2 October 2016; Accepted 19 October 2016

Academic Editor: Manoj K. Mishra

\begin{abstract}
Copyright (C) 2016 Nausicaa Clemente et al. This is an open access article distributed under the Creative Commons Attribution License, which permits unrestricted use, distribution, and reproduction in any medium, provided the original work is properly cited.

Osteopontin (OPN) regulates the immune response at multiple levels. Physiologically, it regulates the host response to infections by driving $\mathrm{T}$ helper (Th) polarization and acting on both innate and adaptive immunity; pathologically, it contributes to the development of immune-mediated and inflammatory diseases. In some cases, the mechanisms of these effects have been described, but many aspects of the OPN function remain elusive. This is in part ascribable to the fact that OPN is a complex molecule with several posttranslational modifications and it may act as either an immobilized protein of the extracellular matrix or a soluble cytokine or an intracytoplasmic molecule by binding to a wide variety of molecules including crystals of calcium phosphate, several cell surface receptors, and intracytoplasmic molecules. This review describes the OPN structure, isoforms, and functions and its role in regulating the crosstalk between innate and adaptive immunity in autoimmune diseases.
\end{abstract}

\section{Introduction}

OPN is an acidic glycoprotein that, depending on its intracellular (iOPN) or extracellular (OPN) localization, is involved in inflammation by inducing cell adhesion and migration, regulating the differentiation of proinflammatory lymphocytes, and inhibiting the apoptosis of inflammatory cells. It was initially described as a bone-specific sialoprotein [1] and then as a molecule expressed in activated T cells, consequently being named the "early T cell activated gene" (ETA-1) [2, 3].

OPN is produced by a variety of cell types, such as B and $\mathrm{T}$ cells, natural killer (NK) cells, NKT cells, macrophages, neutrophils, dendritic cells (DC), bone cells (osteoblasts and osteocytes), breast epithelial cells, and neurons, and high expression is detected in the bone, lung, liver, brain, joints, adipose tissue, and body fluids such as blood, urine, and milk [4-6].
1.1. OPN Gene. OPN is encoded by an $8 \mathrm{~kb}$ gene mapping on chromosome $4 \mathrm{q} 13$ and composed of 7 exons; the first exon is untranslated while exons 2-7 contain the coding sequences (Figure 1). Genetic variations of the OPN gene have been described in the $5^{\prime}$ flanking region, exons, introns and the $3^{\prime}$ untranslated region ( $3^{\prime}$ UTR) [7-9]. Some of these variations are associated with development and/or disease activity of several autoimmune diseases [10-13] and some of them influence OPN expression [14]. For instance, the four single nucleotide polymorphisms (SNPs) $+282 \mathrm{~T}>\mathrm{C}$ (exon VI: rs4754), +750C > T (exon VII; rs1126616), +1083A > G ( $3^{\prime} \mathrm{UTR}$; rs1126772), and $+1239 \mathrm{~A}>\mathrm{C}\left(3^{\prime} \mathrm{UTR}\right.$; rs9138) are associated with three haplotypic combinations, that is, 282T-750C1083A-1239A (haplotype A), 282C-750T-1083A-1239C (haplotype B), and 282C-750T-1083G-1239C (haplotype C), and carriers of haplotype $\mathrm{B}$ and haplotype $\mathrm{C}$ display higher OPN 

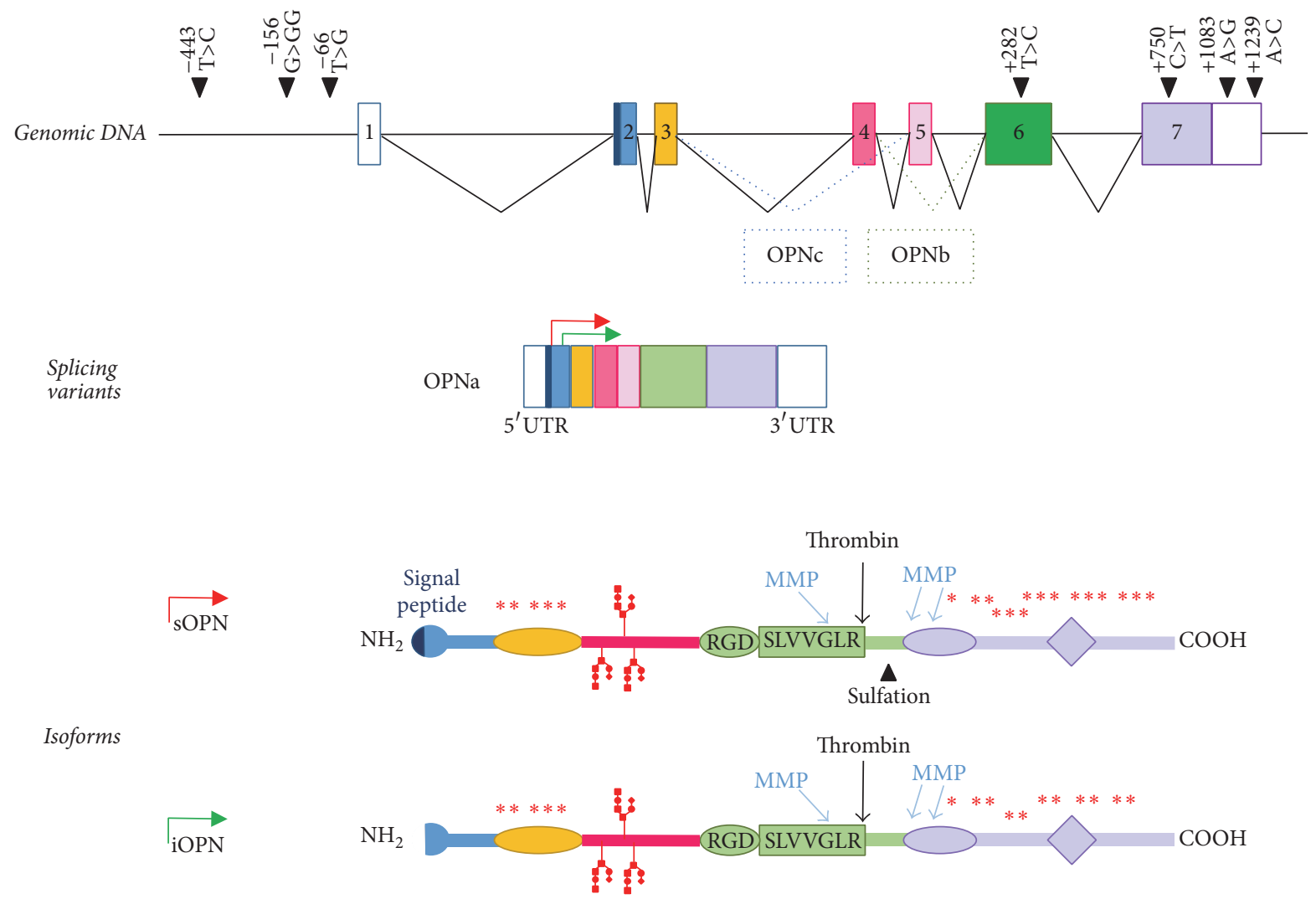

FIGURE 1: Genomic, transcriptional, and protein features of OPN. The figure shows in the upper panel the genomic organization of the SPP1 gene and the relevant single nucleotide polymorphisms. OPN is transcribed with 3 splicing variants: variant a contains exons $2-7$ while variants b and c lack exons 5 and 4, respectively (middle panel). OPN transcripts have also two starting points generating a secreted or/and intracellular form. Several posttranslational modifications are also shown (lower panel) including phosphorylation (asterisks), glycosylation, and sulfation sites. Proteases (thrombin and matrix metalloproteinase, MMP) cleavage sites are also depicted.

serum levels and higher risk of developing several autoimmune diseases than haplotype A homozygotes. This effect may be related to the higher stability of the mRNA coded by haplotype $B$ and haplotype $C$ compared to that coded by haplotype A [15]. Interindividual differences of OPN expression may be also influenced by variations in the promoter region, such as $-66 \mathrm{~T}>\mathrm{G}$ (rs28357094) and -156G>GG (rs7687316) SNPs, which may modulate the transcriptional activity of the gene [15-18]. Table 1 summarizes several associations reported between OPN SNPs and autoimmune diseases (http://www.ncbi.nlm.nih.gov/projects/SNP/) [10, 13-16, 1925].

1.2. OPN Structure. The protein is composed of 314 amino acids, rich in aspartate, glutamate, and serine residues, and it contains functional domains for calcium binding [26]. Its molecular weight ranges from 44 to $75 \mathrm{kDa}$, depending on alternative splicing and posttranslation modifications. Given its composition, OPN is a highly negatively charged protein lacking extensive secondary structure that displays $8 \alpha$-helices and $6 \beta$-sheets. Besides the full-length variant, named OPN-a and containing all exons, two splicing variants are OPN-b and OPN-c lacking exon 5 and exon 4, respectively [27]. All of them use exon 2, which contains the signal peptide, and are expected to be secreted. Another form derives from alternative initiation of transcription, lacks the signal peptide, and is expressed as an intracellular protein (iOPN) (Figure 1). As both OPN and iOPN are generated from the same mRNA, selective silencing of only one of these isoforms is not possible. OPN deficient mice lack both forms, while administration of OPN neutralizing antibodies or aptamers selectively blocks only OPN [28]. Other variants depend on several posttranslational modifications, including phosphorylation, O-linked glycosylation, sialylation, and tyrosine sulfation [29-34].

1.3. OPN Functions. OPN functions as a free cytokine in body fluids or as an immobilized extracellular matrix molecule in mineralized tissue. Its pleiotropic effects are partly due to its capacity to interact with multiple ligands including several cell surface receptors, intracellular signaling molecules, calcium, and heparin.

The binding sites to cell surface receptors include a RGD (arginine-glycine-aspartate) motif interacting with integrins $\alpha \mathrm{v} \beta 1, \alpha \mathrm{v} \beta 3, \alpha \mathrm{v} \beta 5, \alpha \mathrm{v} \beta 6, \alpha 8 \beta 1$, and $\alpha 5 \beta 1$ [35-37], and a binding site for CD44, in particular for the isoform $\mathrm{CD} 44 \mathrm{v}_{6}-\mathrm{v}_{7}$. Moreover, thrombin cleaves OPN at a conserved site $\left({ }^{168} \mathrm{RS}^{169}\right)$ and exposes a cryptic ${ }^{162}$ SVVYGLR $^{168}$ motif 
TABLE 1: OPN gene polymorphisms associated with autoimmune diseases.

\begin{tabular}{lcccc}
\hline SNP & rs & Located & Autoimmune disease & References \\
\hline$-156 \mathrm{G}>\mathrm{GG}$ & Rs7687316 & Promoter & MS, T1D, SLE & {$[15,16,19]$} \\
$-66 \mathrm{~T}>\mathrm{G}$ & Rs28357094 & Promoter & T1D, CD, SLE & {$[10,19,20]$} \\
$+282 \mathrm{~T}>\mathrm{C}($ (8090TH) & Rs4754 & Exon VI & MS, SLE, ALPS/DALD, RA, CD & {$[10,14,21]$} \\
$+750 \mathrm{C}>\mathrm{T}(+707 ; 9250 \mathrm{TH})^{\$}$ & Rs1126616 & Exon VII & SLE $^{\#}$, PBC, MS, CD, ALPS/DALD & {$[10,14,21-23,25]$} \\
$+1083 \mathrm{~A}>\mathrm{G}(9583 \mathrm{RD})^{\$}$ & Rs1126772 & $3^{\prime}$ UTR & BD, SLE ${ }^{*}$, MS, ALPS/DALD, CD & {$[10,13,14,16,21,24,25]$} \\
$+1239 \mathrm{~A}>\mathrm{C}$ & Rs9138 & $3^{\prime} \mathrm{UTR}$ & CD, TDM1, MS, SLE, ALPS/DALD & {$[10,13-16]$} \\
\hline
\end{tabular}

\#* A recent meta-analysis found an association only in Asian but not in European SLE patients (\#) and no association with SLE patients (*) [25].

${ }^{\$}$ SNPs may have different numbering depending on the transcript analysed and the assembly used.

interacting with the integrins $\alpha 9 \beta 1, \alpha 4 \beta 1$, and $\alpha 4 \beta 7[38,39]$. The RGD and the cryptic sites are located in the N-terminal fragment of OPN produced by thrombin cleavage (OPN-N), whereas the $\mathrm{CD} 44$ binding site is located in the corresponding C-terminal fragment (OPN-C).

The role of OPN in the crosstalk between innate and adaptive immunity (iOPN is described later) is clearly highlighted in the development of proinflammatory T helper (Th) type-1 and Th17 cells (Figure 2). By acting on macrophages, OPN upregulates interleukin- (IL-) 12 production and enhances Th1 development. By acting on Th cells, OPN induces production of IL-17 by triggering $\alpha \mathrm{v} \beta 3$ integrin and inhibits secretion of IL-10 by triggering CD44 [40]. By interacting with CD44 in Th cells, OPN induces hypomethylation of interferon- (IFN-) $\gamma$ and $I L-17 a$ genes enhancing differentiation of Th1 and Thl7 cells. In contrast, CD44 deficiency promotes hypermethylation of IFN- $\gamma$ and $I L-17 a$ and hypomethylation of $I L-4$ gene, leading to Th2 cell differentiation [41].

We have recently demonstrated that OPN-N and OPN$\mathrm{C}$ generated by thrombin-mediated cleavage display distinct functions. In T cells, OPN-N promotes IL-17 secretion, whereas OPN-C inhibits IL- 10 secretion. In monocytes, secretion of IL-6 is induced mainly by OPN-N. In several cell types, including vascular endothelial cells and tumor cells, OPN-N induces migration whereas OPN-C induces adhesion. By contrast, both fragments similarly induce IFN- $\gamma$ secretion in T cells and tubulogenesis in vascular endothelial cells and inhibit activation-induced cell death in lymphocytes [42].

Human OPN has two strong heparin-binding domains associated with internalization signals, which suggests that it rapidly binds to surface heparan sulfate proteoglycans to be internalized. Interestingly, the thrombin cleavage site is located close to one of these heparin-binding domain. Thus, heparin binding to OPN blocks the access of thrombin and maintains OPN in the full-length form. Furthermore, the Nterminal of OPN is dominated by acidic, negatively charged amino acids, whereas all of the positively charged heparinbinding domains are on the C-terminal part $[43,44]$.

The biological activity of OPN can be modulated also by cleavage mediated by several matrix metalloproteinases (MMPs), including MMP-1, MMP-2, MMP-3, MMP-8, MMP-9, MMP-10, MMP-11, MMP-12, MMP-13, MMP-14, and MMP-25. These are increased in biological samples of patients with autoimmune diseases, and the majority of them have a detrimental role since their activity inhibit cell adhesion and/or the migration driven by OPN [45, 46]. Human OPN contains three cleavage sites for MMPs located between the amino acids Gly ${ }^{166}-\mathrm{Leu}^{167}, \mathrm{Ala}^{201}-\mathrm{Tyr}^{202}$, and $\mathrm{Asp}^{210}$-Leu $^{211}$. Interestingly, MMP-12 processes OPN into a less-inflammatory form, or, alternatively, it generates OPN peptides with anti-inflammatory properties [47].

Other mechanisms controlling OPN functions are posttranslational modifications, including O-linked glycosylation, sialylation, phosphorylation, and tyrosine sulfation, which influence each other and complicate the functional study on OPN and its variants [48]. For instance, OGlcNAcylation antagonizes phosphorylation in terms of abundance, protein distribution, and activity of the protein [49]. Moreover, reduction of sialylation may prevent OPN from binding to cell surface receptors [31].

OPN displays substantial O-glycosylations, while the level of $\mathrm{N}$-glycosylation seems to be low. Accurate analysis of O-glycosylation on human OPN detected multiple complex and heterogeneous glycans and $\alpha(2-3)$ sialic acids and a novel O-glycosylation site (S146) in the SVVYGLR domain which might regulate the interaction of OPN with integrins $[50,51]$. Additionally, steric hindrance of glycan structures on S146 may impair the OPN cleavage mediated by MMPs. Other O-glycosylation sites are located in the C-terminus of OPN, which binds to CD44 and may regulate various cellular events, including binding interactions [52].

OPN displays 26 phosphorylation sites which may interplay with the O-glycosylation sites [53]. Nevertheless, one new phosphorylation site, Y209, was detected. Interestingly, among the identified O-glycopeptides, aa205-225, aa234252 , and aa286-298 were also identified as phosphorylation sites, indicating that interplay between O-glycosylation and phosphorylation on these sites may occur in OPN.

OPN phosphorylation seems to play regulatory roles in bone mineralization, OPN-receptor interactions, and tumor metastasis [54].

OPN regulates bone mineralization and has diverse effects on hydroxyapatite (HA) formation and growth depending on the extent of phosphorylation, since phosphorylated OPN can bind to $\mathrm{Ca}^{2+}$ and $\mathrm{Mg}^{2+}$ which are essential bone components. Phosphorylated OPN from bone inhibits hydroxyapatite mineral deposition in both cell-free systems [55-58] and in cell cultures [59-62]. In contrast the highly phosphorylated milk OPN promotes mineralization in solution [63]. Moreover, in OPN-KO mice, mineralization is enhanced in bone, calcified cartilage [64], vasculature [65], 


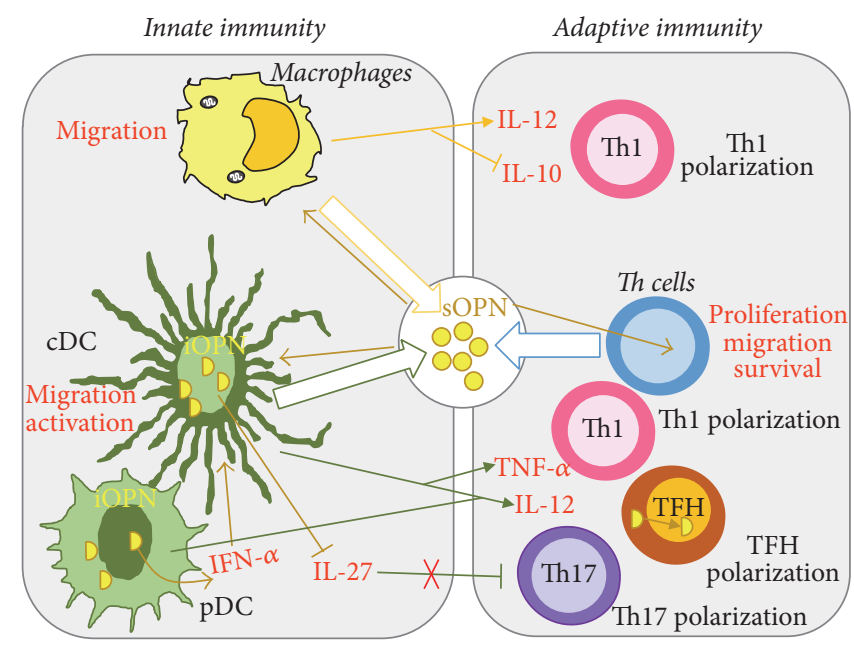

FIGURE 2: OPN mediates innate-adaptive immune crosstalk. Soluble OPN (OPN) acts on macrophages upregulating interleukin- (IL-) 12 production and mediates T helper (Th) 1 development. It also acts on Th cells, inducing the production of IL-17 and inhibiting secretion of IL-10 resulting in Th17 polarization. In conventional dendritic cell (cDC), iOPN inhibits IL-27 expression and enhances the response of Th17 cells. In plasmacytoid DC (pDC), it enhances interferon (IFN) $\alpha$ expression. iOPN has also a key role in T follicular helper (TFH) cells, since during activation iOPN translocate into the nucleus and sustains TFH polarization. Big and empty arrows show OPN production; thin arrows indicate OPN actions.

and kidney [66]. Bovine OPN has two thrombin cleavage sites, thus generating three thrombin-cleaved fragments: an $\mathrm{N}$-terminal, a central, and a C-terminal fragment. These fragments have distinct effects on HA formation and growth: the central fragment is an inhibitor of HA formation, while the C- and N-terminal fragments promote HA formation [67].

Sulphate groups of OPN have been shown to act cooperatively with polyaspartic acid peptides in a $\beta$-sheet structure in promoting HA formation. Accordingly, Nagata et al. showed that sulfation of OPN is important for early formation of $\mathrm{HA}$ crystals in bone, is a valuable indicator of bone formation, and marks the osteoblastic phenotype [68].

1.4. $i O P N$. iOPN was initially found in rat calvarial cells [69] showing two patterns of OPN staining: a perinuclear staining located in the Golgi apparatus and a perimembrane staining reminiscent of focal adhesion staining [69]. In addition, staining was also detected in the nucleus [70]. It was initially suggested that iOPN plays a role mainly in innate immunity, since DCs and macrophages constitutively express high levels of OPN mRNA but secrete relatively small amounts of OPN. By contrast, activated T cells produce $50-$ fold more OPN than macrophages [71, 72]. The function of iOPN seems to be mainly involved in supporting signaling through several receptors. In plasmacytoid DC ( $\mathrm{pDC})$, it is involved in toll-like receptor- (TLR-) 9/TLR-7 by "anchoring" multiple pattern-recognition receptors (PRRs) to form receptor clusters. Moreover, TLR9 ligation promotes association of iOPN and myeloid differentiation primary response gene 88 (MyD88) and enhances IFN- $\alpha$ expression through interferon regulatory factor (IRF) 7 activation. In conventional DC, iOPN inhibits IL-27 expression and enhances the response of Th17. In macrophages, it promotes nuclear translocation of interleukin-1 receptor-associated kinase 1 (IRAK1) and IL-10 expression. Recent data have detected a key role of
iOPN in $\mathrm{T}$ follicular helper (TFH) cells, since inducible $\mathrm{T}$ cell costimulator (ICOS) signaling induces iOPN interaction with the PI3K p $85 \alpha$ regulatory subunit, followed by translocation into the nucleus and binding to $\mathrm{B}$ cell lymphoma(Bcl-) 6 (involved in $\mathrm{TFH}$ differentiation) protecting it from proteasome-mediated degradation [73]. Moreover, at perimembrane regions, iOPN colocalizes with CD44-ERM(ezrin-radixin-moesin-) actin complexes, and it is involved in cell motility [74]; this activity seems to play a key role in the osteoclast function $[75,76]$.

\section{OPN and Autoimmune Diseases}

In the past thirty years, OPN has attracted attention following observations that high levels of OPN can be detected in several autoimmune diseases, like systemic lupus erythematosus (SLE) [77, 78], multiple sclerosis (MS) [79], rheumatoid arthritis (RA) [80], and others [14, 81]. In line with these observations, transgenic overexpression of OPN in a nonautoimmune background causes accumulation of B cells, hypergammaglobulinemia, and production of antiDNA antibodies, which is typical of SLE [82]. Moreover, OPN deficient mice are relatively protected against MS [83], RA [84], type 1 diabetes mellitus (T1DM) [85], autoimmune uveitis [86], autoimmune hepatitis [87, 88], intestinal bowel disease (IBD) [89], and Sjögren's syndrome (SS) [90, 91].

The detrimental activity of OPN in autoimmune diseases may involve its ability to promote secretion of IL-17 and IFN$\gamma$ in T cells and IL- 6 in monocytes, to promote lymphocyte adhesion and migration, to inhibit activation-induced cell death that is involved in the switching off the immune response and to support TFH differentiation (Figure 2).

Genetic investigations, including genome-wide association studies (GWAS), have identified numerous, replicable, 
genetic associations between common SNPs and susceptibility to autoimmune disease, some of which are shared between two or more diseases $[92,93]$. Along with epidemiological and clinical evidence, this suggests that some genetic risk factors may be clustered into groups and influence entire pathways to create risk to multiple diseases [94]. Unexpectedly, no GWAS identified OPN SNPs as associated to any autoimmune disease. Nevertheless, GWAS approach has been enriched and complemented by genome-wide expression profiling, in ex vivo innate (NK and monocytes) or adaptive immune cells (CD4+ T cells, B cells) [92]. Interestingly, genome-wide differential analysis in SLE identified distinct inflammatory pathways involved, including OPN [95].

In this part of the manuscript, we will review the data on SLE, MS, and RA, which display a huge literature related to OPN. They are also mediated by distinct immunopathologic features, since SLE is mainly mediated by antibodies and MS by T cells, whereas RA damage involves bone erosions. Recent advances in other autoimmune diseases are also discussed at the end.

2.1. Systemic Lupus Erythematosus. SLE is a complex autoimmune disease characterized by production of autoantibodies (autoAbs) against nuclear, cytoplasmic, and cell surface molecules that transcend organ-specific boundaries. Tissue deposition of antibodies or immune complexes induces inflammation and subsequent injury of multiple organs and finally results in clinical manifestations of SLE, including glomerulonephritis, dermatitis, thrombosis, vasculitis, and arthritis [96, 97].

The first evidence of a relationship between OPN and SLE was reported in MRL ${ }^{l p r / p r}$ mice, developing a disease partly resembling SLE [98]. MRL ${ }^{l p r / p r}$ mice were found to carry a loss-of-function mutation of the FAS gene, which was followed by identification of the corresponding human disease, which was named autoimmune lymphoproliferative syndrome (ALPS). MRL ${ }^{l p r / p r}$ mice and ALPS patients are characterized by accumulation of polyclonal lymphocytes in the secondary lymphoid organs, expansion of a peculiar subset of T cells expressing TCR $\alpha \beta$ but not CD4 or CD8 (named double negative $\mathrm{T}$ cells) and autoimmune manifestations. MRL ${ }^{l p r / p r}$ mice, but not ALPS patients, produce anti-DNA autoAbs and develop vasculitis, arthritis, and glomerulonephritis causing fatal renal failure [99-101]. In both MRL ${ }^{l p r / l p r}$ mice and ALPS patients, the disease is due to decreased function of the proapoptotic FAS receptor involved in switching off the immune response. Most ALPS patients carry an inherited or somatic loss-of-function mutation of FAS. Rare ALPS patients carry mutations of FASLG coding for FAS-ligand, or CASP10 coding for caspase 10 involved in FAS signaling; a mutation of FASLG is carried also by MRL ${ }^{\text {gld }}$ gld mice showing a disease similar to that displayed by $\mathrm{MRL}^{\text {lpr } / l p r}$ mice. However, a substantial proportion of ALPS patients display a defective function of FAS in the absence of known mutations, which is a pattern shown also by patients with Dianzani autoimmune lymphoproliferative disease (DALD) displaying lymphoproliferation and autoimmune manifestations but lacking DN T cell expansion $[102,103]$.
In mice, $\mathrm{CD}^{-} \mathrm{CD}^{-} \mathrm{T}$ cells expressed high levels of OPN. Overexpression of OPN in MRL ${ }^{l p r / p r}$ mice induces B cell activation and IgG and IgM production, elevated autoantibodies levels (including autoAbs to double-stranded (ds) DNA), and increased cytokine expression (TNF- $\alpha$, IFN- $\gamma$, and IL-1 $\beta)[12,82,97]$. In MRL ${ }^{l p r / l p r}$ mice, OPN upregulation begins at the onset of the autoimmune response and positively correlates with the symptom severity [86], which is also influenced by allelic differences in OPN gene [12, 104], since development of glomerulonephritis is favored by the OPN variant carried by MRL strain but not by the one carried by the $\mathrm{C} 3 \mathrm{H}$ strain. These allelic variants correlate with different levels of antibody production, tumor necrosis factor- (TNF-) $\alpha$, IL- $1 \beta$ and IFN- $\gamma$ expression, and macrophage activation [12]. Similar findings are reported for patients with ALPS or DALD, who show increased levels of serum OPN and an increased risk of developing the diseases in subjects carrying the OPN haplotype B or haplotype $\mathrm{C}$ causing production of high levels of OPN. We proposed that high levels of OPN may contribute to the disease by inhibiting lymphocyte apoptosis, worsening the defect due to defective FAS function [14]. In particular, OPN directly inhibits activation-induced lymphocyte apoptosis and promotes secretion of TIMP1 [105] and IL-17 [106], which, in turn, inhibit both Fas-induced and activation-induced lymphocyte apoptosis.

Increased levels of OPN have been reported also in the sera and plasma of SLE patients $[16,84,107]$, and their use has been suggested in monitoring SLE severity [107]. In line with these observations, a prospectic study suggested that high plasma levels of OPN may be predictors of poor outcome and are associated with the presence of autoAbs anti-ds-DNA and elevated IFN- $\alpha$ levels in the serum [108]. Moreover, high OPN levels in the serum and glomeruli are associated with renal damage, possibly mediated by the OPN's ability to support secretion of Th1 and Th17 proinflammatory cytokines and inflammatory cell migration and activation $[107,109,110]$.

Recently a meta-analysis revealed that the OPN level was significantly higher in SLE patients and particularly in those with renal disease [25]. Moreover, it showed a trend of positive correlation between OPN levels and the systemic lupus erythematosus disease activity index (SLEDAI) [25]. The relationship between OPN and SLE has been confirmed by genetic studies showing correlations between OPN polymorphisms and development of SLE and suggesting that OPN may participate in a complex network of gene-gene and geneenvironment interactions accounting for the SLE clinical heterogeneity. In line with this view, OPN polymorphisms have been correlated with specific clinical features of the disease, such as thrombocytopenia and hemolytic anemia, renal disease and opportunistic infections, lymphadenopathy, and high serum levels of IgE. Moreover, a correlation has been found with high serum levels of IFN- $\alpha$, which is a key cytokine in SLE pathogenesis [16, 20, 22, 111, 112]. Some studies have detected a predominant influence of some polymorphisms on SLE development in males, who account for about $10 \%$ of SLE patients, which suggests that the OPN effect may be highlighted in the absence of strong SLE-promoting factors acting on females [113]. However, other reports have 
detected the same polymorphism as SLE-promoting factors in females and particularly in the young ones $[16,111]$, which may be ascribed to OPN's role in long bone remodeling during adolescence [114]. Other studies investigated OPN 9250C/T (rs1126616) polymorphism as SLE susceptibility variants, in association with OPN levels and clinical outcome. Authors found that the frequency of TT genotypes was higher in SLE patients with nephritis compared to controls, suggesting that the CT and TT genotypes could be risk factors for SLE [115]. Recently, Lee and Song conducted a meta-analysis on the role of OPN in SLE. They found that elevated OPN levels positively correlated with SLE activity and demonstrated a significant association between OPN 1239C/A, 9250C/T polymorphisms, and SLE susceptibility [25].

Interestingly, OPN in kidneys may also be secreted by senescent myofibroblasts and drive glomerular fibrosis [116]. OPN is required for myofibroblasts differentiation, and it regulates the molecules involved in tissue fibrosis. High levels of glomerular OPN are associated with macrophage accumulation and progressive renal injury in an antiglomerular basement membrane (GBM) glomerulonephritis (GN) model $[116,117]$. OPN may modulate also angiotensin-II- (AII-) induced inflammation, oxidative stress, and fibrosis of the kidney [118]. Moreover, studies showed a localization of OPN at the origin of the fibrotic lesion in Bowman's capsule and the OPN deposition colocalized to the fibrotic lesion [116].

OPN also has an important function in vascular inflammation. It acts through modulation of the proliferation, migration, and accumulation of smooth muscle and endothelial cells $[116,119]$. Under injury conditions, OPN plays a regulating role in arterial mineral deposition and in atherosclerotic lesions. OPN levels are high in human atherosclerotic lesions, and in lesions of $\mathrm{ApoE}^{-/-}$mice, a model of atherosclerosis and aneurysm formation especially associated with macrophage and foam cells [120]. In vivo the function of OPN in atherosclerotic plaque formation has been proven by backcrossing $\mathrm{ApoE}^{-/-}$mice with $\mathrm{OPN}^{-/-}$mice. Double knockout mice highlighted the role of OPN in recruiting leukocytes, in macrophage apoptosis, and in reduction of AIIinduced aortic aneurysm formation and MMP-2 and MMP-9 activity. These data support the idea that OPN and MMP have a role in regulation and vessel rupture [120].

2.2. Multiple Sclerosis. MS is a chronic inflammatory disease of the Central Nervous System (CNS). At onset, approximately $15 \%$ of patients display a primary progressive course $(\mathrm{PP})$, whereas the others display a relapsing-remitting (RR) course, which mostly switches to a secondary progressive (SP) course within 10-15 years [121]. Analysis of the transcriptome has identified more than 50 genes highly overexpressed in MS lesions, and they included OPN [122]. High OPN levels have been reported in the serum, plasma, and cerebrospinal fluid (CFS) of MS patients and levels are higher in RR MS than in PP and SP MS, especially during the relapses. Moreover, OPN is expressed in reactive astrocytes and microglial cells in patients with RR-MS, particularly during the relapses [123128]. The high OPN levels are positively correlated with the levels of IL-17 $[129,130]$.
Genetic analyses have associated variations of the $O P N$ gene with MS [21, 131]. In this regard, we found that the variants of the $O P N$ gene coding for a mRNA with increased stability (haplotype B and haplotype C) were associated with increased risk of MS, severe disease course, and rapid evolution of disability [132]. Furthermore, we detected a correlation between the $156 \mathrm{G}>\mathrm{GG}$ SNP in the OPN promoter region and timing of disability progression and switch to the SP form [15, 132]. In Japanese patients, an OPN SNP (i.e., $9583 \mathrm{~A}>\mathrm{G}$ ) has been associated with age of onset of disease [21]. However, other studies have not found associations between OPN variants and MS development or course [131].

Experimental autoimmune encephalomyelitis (EAE), the animal model of MS, is mediated by myelin specific autoreactive Th1 and Thl7 cells. OPN deficient mice develop an attenuated form of EAE with a single relapse and lack of exacerbations or progression [79]. From the immunological point of view, they show a shift toward a Th2 cytokine profile, a reduction of proinflammatory cytokines, such as IFN- $\gamma$, and TNF- $\alpha$, and increased numbers of apoptotic immune cells in the CNS lesions. Moreover, daily treatment with recombinant OPN worsened EAE in $\mathrm{OPN}^{+/+}$mice and the effect was even more striking in OPN deficient mice. These results suggest that OPN influences the disease course not only by supporting expression of proinflammatory cytokines, but also by inhibiting apoptosis of autoreactive immune [133]. Treatment with IFN- $\beta$ suppressed the production of IL-17 and OPN, through activation of signal transducer and activator of transcription (STAT)1 and suppression of STAT3 activity, and decreased spinal cord infiltration of cells secreting OPN and IL- 17 [130].

Proteomic studies performed on MS lesions have detected the expression of several molecules of the coagulation cascade and administration of coagulation inhibitors, such as hirudin, decreased disease severity, and suppressed production of Th1 and Th17 type cytokines [79, 133, 134]. These effects may involve OPN, since thrombin cleavage unmasks the OPN cryptic domain interacting with $\alpha 4 \beta 1$ integrin. This plays a key role in the recruitment of autoimmune T cells in MS lesions and is targeted by natalizumab, a humanized monoclonal antibody active in the treatment of RR MS [135]. Moreover, $\alpha 4 \beta 1$-OPN interaction prevents nuclear translocation of the transcription factor forkhead box O3A (FOXO3A), blocking transcription of proapoptotic genes such as Bim, Bcl2 homologous antagonist killer (Bak), and Bcl-2-associated $\mathrm{X}$ protein (Bax), and promotes degradation of $\mathrm{Ik}-\mathrm{B}$ with activation of NF-kB and upregulation of antiapoptotic genes and Th1 and Th17 cytokines [136].

A modulatory effect on OPN activity may also be exerted by OPN cleavage by MMPs whose levels are increased in several autoimmune diseases [45]. In line with this view, MMP12-deficient mice develop more severe EAE than wild type mice, and this effect disappears in OPN/MMP-12 doubledeficient mice $[46,47]$.

It has been reported that, after spinal cord injury, OPN is expressed by microglia and correlated with cell infiltration. OPN plays a major role in attracting inflammatory cells to the injury site [137] and, for a long time, most authors highlighted 
the role of OPN in exacerbating tissue damage after spinal cord injury. By contrast, Hashimoto et al. observed that the expression of Bcl-2, TNF- $\alpha$, IL- $1 \beta$, and IL- 6 is downregulated in OPN knockout spinal cord after spinal cord injury that may result from a deficiency of OPN's proinflammatory activity [138]. Lower cytokine expression is accompanied by reduction of the number and activity of microglia/macrophages. Moreover, KO mice showed lower Basso Mouse Scale (BMS) scores than in wild type mice. These findings suggest that OPN is beneficial for recovery from spinal cord injury and plays a neuroprotective role during inflammatory response to spinal cord injury. This is also supported by research showing an upregulation of OPN, secreted by astrocytes and microglial cells, during the demyelination and remyelination, at the site of spinal cord injury [139]. A stroke model, too, in which focal cerebral ischemia is induced by photothrombosis, has shown a neuroprotective and regenerative function of OPN, especially when it is cleaved by thrombin [140].

2.3. Rheumatoid Arthritis. RA is a chronic, disabling autoimmune disease characterized by an inflammatory attack of the joint space, leading to the invasive growth of the synovial tissue and progressive destruction of the articular cartilage and bone [141]. RA patients have a shortened life span, and they suffer cardiovascular diseases caused by accelerated atherosclerosis which are a common cause of death in these patients. In the diseased joints, several cytokines are highly expressed, including OPN together with IL-1 and TNF- $\alpha$ [142].

The first evidence of a relationship between OPN and $\mathrm{RA}$ was provided in $\mathrm{OPN}^{-/-}$mice that are protected from joint destruction in collagen-antibody-induced arthritis, an RA animal model (CAIA) [84]. High levels of OPN have been reported in the plasma and synovial fluid of RA patients [143] and have been associated with clinical severity indexes [144]. Furthermore, OPN mRNA is highly expressed in $\mathrm{CD}^{+}$ synovial $\mathrm{T}$ cells and correlates with coexpression of selected OPN receptors, including $\alpha \mathrm{v}$ and $\beta 1$ integrin chains and CD44 [145]. Moreover, OPN plasma levels decrease after treatment with biologics or immunosuppressive drugs [145].

The effects of OPN on bone resorption are mainly ascribed to the interaction with CD44 and $\alpha \mathrm{v} \beta 3$ integrin expressed by osteoclasts in the site of bone erosion [146]. However, other receptors may also be involved, since blocking $\alpha v \beta 3$ integrin by means of anti- $\beta 3$ antibodies or other specific antagonists, such as SB273005 or cyclic RGD peptides, inhibits bone resorption only partly in animal models of RA [147].

Integrins $\alpha 4$ and $\beta 9$ chains are expressed in arthritic joints and mAbs against the cryptic domain of OPN ameliorate collagen-induced arthritis by decreasing infiltration of inflammatory cells, proliferation of synovium, and development of bone erosions [148]. In line with a role of the cryptic domain, high levels of thrombin, OPN-N, and OPN$\mathrm{C}$ have been detected in the synovial fluid of patients with RA. The levels of OPN-C and OPN-N correlate with the disease's severity, and the thrombin inhibitor hirudin ameliorates collagen-induced arthritis [149]. Moreover, the activity of OPN-N may be inhibited by thrombin-activatable carboxypeptidase $\mathrm{B}(\mathrm{CPB})$, which cleaves the C-terminal arginine from the cryptic site [150]. Interestingly, RA synoviocytes express a modified form of OPN, forming a complex with fibronectin and thus exposing the cryptic domain that promotes secretion of IL-6 in B cells [151].

In RA, OPN may play a crucial role by promoting differentiation of Th17 and Thl cells, whose levels are elevated in rheumatoid synovium and correlate with several parameters of inflammation in RA patients [152]. Genetic studies did not detect univocal associations of $O P N$ variants with RA. Some studies did not find any association between OPN polymorphisms and susceptibility to RA nor any correlation between OPN levels and OPN genetic polymorphisms [153, 154]. By contrast, an Italian study associated a SNP in the OPN promoter region $(-156 \mathrm{G}>\mathrm{GG})$ with RA susceptibility [155]. These differences may be ascribed to the different influence of other concurrent genetic or environmental factors in the different populations of patients.

A recent prospective study, conducted in biologic-naïve patients with RA, pointed out that low OPN serum levels at baseline predict clinical remission one year after initiating tocilizumab treatment but not infliximab treatment [156].

OPN is also a crucial regulator involved in osteoarthritis (OA) progression [157]. OA is the most common form of arthritis, which mainly affects older people. OPN is highly expressed in the joints of OA patients, and its levels correlate with the severity of joint lesion and inflammatory status in the OA patients [158]. Abnormal mechanical load to chondrocytes alters the composition and metabolism of articular cartilage [159], which induces the release of OPN, and the enhanced level of OPN in cartilage leads to the induction of MMP-13 [160]. MMP-13 is thought to be involved in the degradation of cartilage matrix components of type II collagen and the release of proteoglycan from cartilage tissue that promotes the development of OA [161]. Elevated levels of OPN in cartilage also activate the transcription factor NF- $\kappa \mathrm{B}$ pathway involved in the production of many inflammatory factors, including chemokines and cytokines (e.g., IL-1, IL6, IL-8, CXCL1, and CCL2) in cartilage, which leads to the spontaneous production of nitric oxide (NO), prostaglandin E2 (PGE2), IL-1 $\beta$, IL-6, and IL-8. The overproduction of these cytokines and mediators exerts injurious effects on chondrocyte functions which lead to an imbalance of cartilage homeostasis resulting in progressive articular degeneration [162].

\subsection{Other Autoimmune Diseases}

2.4.1. Type 1 Diabetes Mellitus (T1DM). In T1DM, the autoimmune process is marked by the presence of antiglutamic acid decarboxylase (GAD), anti-islet cell, or anti-insulin antibodies, but the disease is mainly due to cell-mediated destruction of insulin-producing pancreatic $\beta$-cells [163]. This destruction is preceded by insulitis, a massive invasion of the islets by a mixed population of lymphocytes and macrophages. OPN may play a role in this inflammation since serum levels are increased in T1DM compared to controls and in diabetic patients correlated with high systolic and diastolic blood pressure, body mass index, low high density lipoprotein, diagnosis of retinopathy, and microalbuminuria 
$[164,165]$. High OPN concentrations are associated with an unfavorable metabolic profile in these patients and are strong predictors of incipient diabetic nephropathy $[164,166]$. SNPs analysis of the OPN gene showed that $+1239 \mathrm{C}$ carriers displayed a significantly higher risk of T1DM than +1239 A homozygotes [13]. Another SNP that can have a susceptibility role in T1DM development is located in the position 66. The $\mathrm{G}$ allele had significantly higher frequency in controls than T1DM patients. Interestingly, case-control comparison in males showed no significant association, whereas the association was confirmed in females [19]. Intriguingly, a screening of random peptide libraries with sera of young T1D patients detected an epitope of human OPN as an autoantigen expressed in the somatostatin cells of human islets [167].

2.4.2. Sjögren's Syndrome (SS). SS is an autoimmune disease characterized by lymphocyte infiltration of exocrine glands but can also involve the lungs, kidneys, and nervous system. Moreover, patients with SS are predisposed to develop nonHodgkin's B cell lymphoma at a substantially higher rate than the general population. Recent studies suggested a role for OPN in SS pathogenesis $[168,169]$ since OPN levels are increased in the serum and salivary glands of patients with SS. Transgenic mice expressing OPN under the immunoglobulin enhancer/SV40 promoter spontaneously develop SS and display increased OPN levels both in the salivary glands and systemically. In tissues, OPN colocalizes with the inflammatory infiltration and is associated with reduced saliva production and increased autoantibody levels. These data have been confirmed in both the serum and submandibular salivary gland tissue using the well-characterized NOD/ShiLtJ mice, developing spontaneous SS disease in a highly predictable time frame [170]. Since OPN transgenic mice showed elevated OPN levels especially in B cell, B cell derived OPN has been speculated to play a role in SS development [90], even if a role may be played also by $\mathrm{T}$ cell derived OPN, and IOPN in TFH cells [73].

2.4.3. Inflammatory Bowel Diseases (IBD). IBDs are immunemediated diseases typically resulting from abnormal mucosal $\mathrm{T}$ cell response to commensal bacteria in intestine and involve chronic intestinal inflammation, mucosal damage, and epithelial barrier dysfunction. Plasma concentration of OPN is elevated in patients with ulcerative colitis (UC) and correlate with clinical activity [81]. Moreover, Crohn's disease (CD) patients show elevated OPN expression in the terminal ileum and elevated plasma OPN levels correlate with disease activity [171-175]. In particular, in patients with active disease, the plasma OPN levels were increased compared with the quiescent disease and reduced after infliximab treatment. Genetic studies also found association of OPN haplotypes with $\mathrm{CD}$ susceptibility, and the combined effects of certain OPN variants may modulate IL-22 secretion [10]. However, preclinical studies showed that, in the acute phase of colitis, OPN-KO mice showed more extensive colonic ulcerations and mucosal destruction than wild type mice and the clinical phenotype was ameliorated by delivery of OPN. By contrast, in chronic dextran sulfate sodium- (DSS-) induced colitis, in which a Thl response of the lamina propria infiltrates played a pivotal role, OPN-KO mice were protected from mucosal inflammation and produced less serum levels of IL-12 than wild type mice. Furthermore, neutralization of OPN was therapeutic in these mice. These data suggest a dual function of OPN in intestinal inflammation: during acute inflammation it activates innate immunity, reducing tissue damage and initiating mucosal repair; during chronic inflammation, it activates adaptive Thl response, reducing inflammation [176].

2.5. Targeting OPN in Autoimmune Diseases. Patients with with RA or OA spontaneously produce anti-OPN autoAbs, and their serum levels are inversely correlated with markers of disease activity [177]. These data are in line with a large body of data showing that autoAbs against inflammatory cytokines can be detected in several inflammatory diseases and suggesting that they are a physiological mechanism to counteract the pathological effects of these cytokines [178]. In line with this model, induction of EAE promotes the production of antiOPN autoAbs, and remission occurs when their titers peak. Furthermore, DNA vaccination with a plasmid encoding OPN before EAE induction boosts the production of these autoAbs and ameliorates the course of the disease [179]. In MS, we found increased levels of anti-OPN autoAbs in RR MS patients especially in the early phases of the disease and during the remission phase. Moreover, high levels of anti-OPN autoAbs at diagnosis correlate with relented development of disability in the RR MS patients treated with immunomodulating therapy.

These data suggest that the use of antagonists of OPN may be effective in the treatment of autoimmune diseases. In line with this possibility, injection of anti-OPN antibodies ameliorates the disease in primate and mouse RA [84]. These experiments showed that this cryptic epitope is involved in leukocytes migration, cell adhesion, cytokine production, and progression of arthritis [180]. Moreover, in a rat model of antiglomerular basement membrane glomerulonephritis, induced by immunizing mice with the nephritogenic $\mathrm{T}$ cell epitope pCol(28-40) derived from $\alpha 3$ chain of type IV collagen, treatment with neutralizing antibodies to OPN inhibited development of glomerular fibrosis [117].

These results obtained in animal models have prompted a recent study on safety, tolerability, pharmacokinetics, pharmacodynamic, and efficacy of a monoclonal antibody against OPN in patients with RA [180]. Patients with RA were divided into two random groups, that is, treated with a placebo or a humanized IgG1 monoclonal antibody (ASK8007) directed to the cryptic site of OPN and inhibiting both RGD- and $\alpha 9 \beta 1$ integrin-dependent cell binding to human OPN [180, 181]. Overall ASK8007 administration appeared safe and well tolerated up to a highest dose $(20 \mathrm{mg} / \mathrm{kg})$, but it did not induce any improvement in joint inflammation and destruction. This can be the consequence of the clinical trial design (early time of evaluation, low power of the study, and aggressive disease compared to the mild preclinical one), low affinity of the $\mathrm{mAb}$ for the human OPN, or the methodology used targeting OPN but not iOPN. To overcome this problem, silencing OPN expression might be a good approach since mice with collagen-induced arthritis ameliorated the inflammatory 
response and bone destruction (articular swelling and cartilage erosion) in the ankle joint upon inhibition of OPN expression, by mean of lentiviral OPN short hairpin RNA [182]. Moreover, preclinical data on experimental autoimmune uveitis, in which targeting of OPN has been obtained by mean of a small interfering RNA (siRNA) [183], are encouraging.

Results showed that plasma levels of OPN and the clinical and histopathological scores of disease were lower in the siRNA-treated group than that in the control group.

\section{Conclusions}

OPN is multifaceted protein exerting several roles in inflammation, adaptive immunity, tissue repair, bone formation, and cell signaling. These heterogeneous activities may be ascribed to the multiple variants of OPN including those due to transcriptional, posttranscriptional, and posttranslational modifications. These variants may be variably involved in the pathogenesis of different autoimmune diseases and clarification of the role of each variants is crucial to tailor appropriate therapeutic approaches targeting this complex molecule.

\section{Competing Interests}

The authors declare that they have no competing interests.

\section{Acknowledgments}

This research was supported by the Fondazione Italiana Sclerosi Multipla (FISM, Genova 2010/R/12-2011/R/11), the Associazione Italiana Ricerca sul Cancro (IG 14430, AIRC, Milan), Fondazione Amici di Jean (Torino), and Fondazione Cassa di Risparmio di Cuneo (Cuneo).

\section{References}

[1] F. P. Ross, J. Chappel, J. I. Alvarez et al., "Interactions between the bone matrix proteins osteopontin and bone sialoprotein and the osteoclast integrin $\alpha \mathrm{v} \beta 3$ potentiate bone resorption," Journal of Biological Chemistry, vol. 268, no. 13, pp. 9901-9907, 1993.

[2] A. Oldberg, A. Franzen, and D. Heinegard, "Cloning and sequence analysis of rat bone sialoprotein (osteopontin) cDNA reveals an Arg-Gly-Asp cell-binding sequence," Proceedings of the National Academy of Sciences of the United States of America, vol. 83, no. 23, pp. 8819-8823, 1986.

[3] R. Patarca, G. J. Freeman, R. P. Singh et al., "Structural and functional studies of the early T lymphocyte activation 1 (Eta-1) gene. Definition of a novel T cell-dependent response associated with genetic resistance to bacterial infection," The Journal of Experimental Medicine, vol. 170, no. 1, pp. 145-161, 1989.

[4] D. T. Denhardt and M. Noda, "Osteopontin expression and function: role in bone remodeling," Journal of Cellular Biochemistry. Supplement, vol. 30-31, pp. 92-102, 1998.

[5] S. K. Ramaiah and S. Rittling, "Role of osteopontin in regulating hepatic inflammatory responses and toxic liver injury," Expert Opinion on Drug Metabolism \& Toxicology, vol. 3, no. 4, pp. 519526, 2007.
[6] T. Uede, "Osteopontin, intrinsic tissue regulator of intractable inflammatory diseases,” Pathology International, vol. 61, no. 5, pp. 265-280, 2011.

[7] F. Giacopelli, N. Rosatto, M. T. Divizia, R. Cusano, G. Caridi, and R. Ravazzolo, "The first intron of the human osteopontin gene contains a C/EBP-beta-responsive enhancer," Gene Expression, vol. 11, no. 2, pp. 95-104, 2003.

[8] H. Iwasaki, Y. Shinohara, Y. Ezura et al., "Thirteen singlenucleotide polymorphisms in the human osteopontin gene identified by sequencing of the entire gene in Japanese individuals," Journal of Human Genetics, vol. 46, no. 9, pp. 544-546, 2001.

[9] S. Mochida, M. Hashimoto, A. Matsui et al., "Genetic polymorphims in promoter region of osteopontin gene may be a marker reflecting hepatitis activity in chronic hepatitis C patients," Biochemical and Biophysical Research Communications, vol. 313, no. 4, pp. 1079-1085, 2004.

[10] J. Glas, J. Seiderer, C. Bayrle et al., "The role of osteopontin (OPN/SPP1) haplotypes in the susceptibility to Crohn's disease," PLoS ONE, vol. 6, no. 12, Article ID e29309, 2011.

[11] N. Barizzone, M. Marchini, F. Cappiello et al., "Association of osteopontin regulatory polymorphisms with systemic sclerosis," Human Immunology, vol. 72, no. 10, pp. 930-934, 2011.

[12] T. Miyazaki, M. Ono, W.-M. Qu et al., "Implication of allelic polymorphism of osteopontin in the development of lupus nephritis in MRL/lpr mice," European Journal of Immunology, vol. 35 , no. 5, pp. 1510-1520, 2005.

[13] A. Chiocchetti, E. Orilieri, G. Cappellano et al., "The osteopontin gene $+1239 \mathrm{~A} / \mathrm{C}$ single nucleotide polymorphism is associated with type 1 diabetes mellitus in the Italian population," International Journal of Immunopathology and Pharmacology, vol. 23, no. 1, pp. 263-269, 2010.

[14] A. Chiocchetti, M. Indelicato, T. Bensi et al., "High levels of osteopontin associated with polymorphisms in its gene are a risk factor for development of autoimmunity/lymphoproliferation," Blood, vol. 103, no. 4, pp. 1376-1382, 2004.

[15] C. Comi, G. Cappellano, A. Chiocchetti et al., "The impact of osteopontin gene variations on multiple sclerosis development and progression," Clinical and Developmental Immunology, vol. 2012, Article ID 212893, 6 pages, 2012.

[16] S. D’Alfonso, N. Barizzone, M. Giordano et al., "Two singlenucleotide polymorphisms in the $5 \prime$ and $3 /$ ends of the osteopontin gene contribute to susceptibility to systemic lupus erythematosus," Arthritis and Rheumatism, vol. 52, no. 2, pp. 539-547, 2005.

[17] S. Mochida, T. Yoshimoto, S. Mimura et al., "Transgenic mice expressing osteopontin in hepatocytes as a model of autoimmune hepatitis," Biochemical and Biophysical Research Communications, vol. 317, no. 1, pp. 114-120, 2004.

[18] F. Giacopelli, R. Marciano, A. Pistorio et al., "Polymorphisms in the osteopontin promoter affect its transcriptional activity," Physiological Genomics, vol. 15, no. 1, pp. 87-96, 2004.

[19] R. Marciano, G. D’Annunzio, N. Minuto et al., "Association of alleles at polymorphic sites in the osteopontin encoding gene in young type 1 diabetic patients," Clinical Immunology, vol. 131, no. 1, pp. 84-91, 2009.

[20] T. Trivedi, B. S. Franek, S. L. Green et al., "Osteopontin alleles are associated with clinical characteristics in systemic lupus erythematosus," Journal of Biomedicine and Biotechnology, vol. 2011, Article ID 802581, 2011.

[21] M. Niino, S. Kikuchi, T. Fukazawa, I. Yabe, and K. Tashiro, "Genetic polymorphisms of osteopontin in association with 
multiple sclerosis in Japanese patients," Journal of Neuroimmunology, vol. 136, no. 1-2, pp. 125-129, 2003.

[22] A. C. Forton, M. A. Petri, D. Goldman, and K. E. Sullivan, "An osteopontin (SPP1) polymorphism is associated with systemic lupus erythematosus," Human Mutation, vol. 19, no. 4, p. 459, 2002.

[23] K. Kikuchi, A. Tanaka, H. Miyakawa et al., "Eta-1/osteopontin genetic polymorphism and primary biliary cirrhosis," Hepatology Research, vol. 26, no. 2, pp. 87-90, 2003.

[24] M. Chu, P. Yang, S. Hou, F. Li, Y. Chen, and A. Kijlstra, "Behçet's disease exhibits an increased osteopontin serum level in active stage but no association with osteopontin and its receptor gene polymorphisms," Human Immunology, vol. 72, no. 6, pp. 525529, 2011.

[25] Y. H. Lee and G. G. Song, "Correlation between circulating osteopontin level in systemic lupus erythematosus and disease activity and associations between osteopontin polymorphisms and disease susceptibility: a meta-analysis," Lupus, 2016.

[26] E. Kläning, B. Christensen, E. S. Sørensen, T. Vorup-Jensen, and J. K. Jensen, "Osteopontin binds multiple calcium ions with high affinity and independently of phosphorylation status," Bone, vol. 66, pp. 90-95, 2014.

[27] M. F. Young, J. M. Kerr, J. D. Termine et al., "cDNA cloning, mRNA distribution and heterogeneity, chromosomal location, and RFLP analysis of human osteopontin (OPN)," Genomics, vol. 7, no. 4, pp. 491-502, 1990.

[28] J. D. Coombes, M. Swiderska-Syn, L. Dollé et al., "Osteopontin neutralisation abrogates the liver progenitor cell response and fibrogenesis in mice," Gut, vol. 64, pp. 1120-1131, 2014.

[29] M. Nemir, M. W. DeVouge, and B. B. Mukherjee, "Normal rat kidney cells secrete both phosphorylated and nonphosphorylated forms of osteopontin showing different physiological properties," The Journal of Biological Chemistry, vol. 264, no. 30, pp. 18202-18208, 1989.

[30] G. F. Weber, S. Zawaideh, S. Hikita, V. A. Kumar, H. Cantor, and S. Ashkar, "Phosphorylation-dependent interaction of osteopontin with its receptors regulates macrophage migration and activation," Journal of Leukocyte Biology, vol. 72, no. 4, pp. 752761, 2002.

[31] V. Shanmugam, I. Chackalaparampil, G. C. Kundu, A. B. Mukherjee, and B. B. Mukherjee, "Altered sialylation of osteopontin prevents its receptor-mediated binding on the surface of oncogenically transformed tsB77 cells," Biochemistry, vol. 36, no. 19, pp. 5729-5738, 1997.

[32] B. Christensen, C. C. Kazanecki, T. E. Petersen, S. R. Rittling, D. T. Denhardt, and E. S. Sørensen, "Cell type-specific posttranslational modifications of mouse osteopontin are associated with different adhesive properties," The Journal of Biological Chemistry, vol. 282, no. 27, pp. 19463-19472, 2007.

[33] K. Singh, M. W. DeVouge, and B. B. Mukherjee, "Physiological properties and differential glycosylation of phosphorylated and nonphosphorylated forms of osteopontin secreted by normal rat kidney cells," The Journal of Biological Chemistry, vol. 265, no. 30, pp. 18696-18701, 1990.

[34] B. He, M. Mirza, and G. F. Weber, "An osteopontin splice variant induces anchorage independence in human breast cancer cells," Oncogene, vol. 25, no. 15, pp. 2192-2202, 2006.

[35] S. Denda, U. Müller, K. L. Crossin, H. P. Erickson, and L. F. Reichardt, "Utilization of a soluble integrin-alkaline phosphatase chimera to characterize integrin $\alpha 8 \beta 1$ receptor interactions with tenascin: murine $\alpha 8 \beta 1$ binds to the RGD site in tenascin-C fragments, but not to native tenascin-C, Biochemistry, vol. 37, no. 16, pp. 5464-5474, 1998.

[36] D. D. Hu, J. R. Hoyer, and J. W. Smith, " $\mathrm{Ca}^{2+}$ suppresses cell adhesion to osteopontin by attenuating binding affinity for integrin $\alpha_{\mathrm{v}} \beta_{3}$," The Journal of Biological Chemistry, vol. 270, no. 17, pp. 9917-9925, 1995.

[37] Y. Yokosaki, K. Tanaka, F. Higashikawa, K. Yamashita, and A. Eboshida, "Distinct structural requirements for binding of the integrins $\alpha \mathrm{v} \beta 6, \alpha \mathrm{v} \beta 3, \alpha \mathrm{v} \beta 5, \alpha 5 \beta 1$ and $\alpha 9 \beta 1$ to osteopontin," Matrix Biology, vol. 24, no. 6, pp. 418-427, 2005.

[38] P. M. Green, S. B. Ludbrook, D. D. Miller, C. M. T. Horgan, and S. T. Barry, "Structural elements of the osteopontin SVVYGLR motif important for the interaction with $\alpha_{4}$ integrins," FEBS Letters, vol. 503, no. 1, pp. 75-79, 2001.

[39] K. Ito, S. Kon, Y. Nakayama et al., "The differential amino acid requirement within osteopontin in $\alpha 4$ and $\alpha 9$ integrinmediated cell binding and migration," Matrix Biology, vol. 28, no. 1, pp. 11-19, 2009.

[40] G. Murugaiyan, A. Mittal, and H. L. Weiner, "Increased osteopontin expression in dendritic cells amplifies IL-17 production by CD4+ T cells in experimental autoimmune encephalomyelitis and in multiple sclerosis," The Journal of Immunology, vol. 181, no. 11, pp. 7480-7488, 2008.

[41] H. Guan, P. S. Nagarkatti, and M. Nagarkatti, "Role of CD44 in the differentiation of Th1 and Th2 cells: CD44-deficiency enhances the development of Th2 effectors in response to sheep $\mathrm{RBC}$ and chicken ovalbumin," Journal of Immunology, vol. 183, no. 1, pp. 172-180, 2009.

[42] E. Boggio, C. Dianzani, C. L. Gigliotti et al., "Thrombin cleavage of osteopontin modulates its activities in human cells in vitro and mouse experimental autoimmune encephalomyelitis in vivo," Journal of Immunology Research, vol. 2016, Article ID 9345495, 13 pages, 2016.

[43] G. Platzer, A. Schedlbauer, A. Chemelli et al., "The metastasisassociated extracellular matrix protein osteopontin forms transient structure in ligand interaction sites," Biochemistry, vol. 50, no. 27, pp. 6113-6124, 2011.

[44] Metastasis, Osteopontin, Heparin Cooling Inflammation Blog, http://coolinginflammation.blogspot.it/2008/10/metastasisosteopontin-heparin.html.

[45] R. Agnihotri, H. C. Crawford, H. Haro, L. M. Matrisian, M. C. Havrda, and L. Liaw, "Osteopontin, a novel substrate for matrix metalloproteinase-3 (stromelysin-1) and matrix metalloproteinase-7 (matrilysin)," The Journal of Biological Chemistry, vol. 276, no. 30, pp. 28261-28267, 2001.

[46] H. Masuda, Y. Takahashi, S. Asai, and T. Takayama, "Distinct gene expression of osteopontin in patients with ulcerative colitis," Journal of Surgical Research, vol. 111, no. 1, pp. 85-90, 2003.

[47] A. G. DaSilva, L. Liaw, and V. W. Yong, "Cleavage of osteopontin by matrix metalloproteinase-12 modulates experimental autoimmune encephalomyelitis disease in C57BL/6 mice," American Journal of Pathology, vol. 177, no. 3, pp. 1448-1458, 2010.

[48] P. Beltrao, P. Bork, N. J. Krogan, and V. Van Noort, "Evolution and functional cross-talk of protein post-translational modifications," Molecular Systems Biology, vol. 9, no. 1, article 714, 2013.

[49] A. M. Butt, D. Feng, M. Idrees, Y. Tong, and J. Lu, "Computational identification and modeling of crosstalk between phosphorylation, $\mathrm{O}-\beta$-glycosylation and methylation of FoxO3 and implications for cancer therapeutics," International Journal of Molecular Sciences, vol. 13, no. 3, pp. 2918-2938, 2012. 
[50] M. Keykhosravani, A. Doherty-Kirby, C. Zhang et al., "Comprehensive identification of post-translational modifications of rat bone osteopontin by mass spectrometry," Biochemistry, vol. 44, no. 18, pp. 6990-7003, 2005.

[51] B. Christensen, M. S. Nielsen, K. F. Haselmann, T. E. Petersen, and E. S. Sørensen, "Post-translationally modified residues of native human osteopontin are located in clusters: identification of 36 phosphorylation and five O-glycosylation sites and their biological implications," Biochemical Journal, vol. 390, no. 1, pp. 285-292, 2005.

[52] H. Rangaswami, A. Bulbule, and G. C. Kundu, "Osteopontin: role in cell signaling and cancer progression," Trends in Cell Biology, vol. 16, no. 2, pp. 79-87, 2006.

[53] H. Li, H. Shen, G. Yan et al., "Site-specific structural characterization of O-glycosylation and identification of phosphorylation sites of recombinant osteopontin," Biochimica et Biophysica Acta-Proteins and Proteomics, vol. 1854, no. 6, pp. 581-591, 2015.

[54] Y. Kariya, M. Kanno, K. Matsumoto-Morita, M. Konno, Y. Yamaguchi, and Y. Hashimoto, "Osteopontin O-glycosylation contributes to its phosphorylation and cell-adhesion properties," The Biochemical Journal, vol. 463, no. 1, pp. 93-102, 2014.

[55] A. L. Boskey, M. Maresca, W. Ullrich, S. B. Doty, W. T. Butler, and C. W. Prince, "Osteopontin-hydroxyapatite interactions in vitro: inhibition of hydroxyapatite formation and growth in a gelatin-gel," Bone and Mineral, vol. 22, no. 2, pp. 147-159, 1993.

[56] A. L. Boskey, "Osteopontin and related phosphorylated sialoproteins: effects on mineralization," Annals of the New York Academy of Sciences, vol. 760, pp. 249-256, 1995.

[57] G. K. Hunter, P. V. Hauschka, A. R. Poole, L. C. Rosenberg, and H. A. Goldberg, "Nucleation and inhibition of hydroxyapatite formation by mineralized tissue proteins," Biochemical Journal, vol. 317, no. 1, pp. 59-64, 1996.

[58] H. A. Goldberg, K. J. Warner, M. C. Li, and G. K. Hunter, "Binding of bone sialoprotein, osteopontin and synthetic polypeptides to hydroxyapatite," Connective Tissue Research, vol. 42, no. 1, pp. 25-37, 2001.

[59] S. Jono, C. Peinado, and C. M. Giachelli, "Phosphorylation of osteopontin is required for inhibition of vascular smooth muscle cell calcification," Journal of Biological Chemistry, vol. 275, no. 26, pp. 20197-20203, 2000.

[60] A. L. Boskey, S. B. Doty, V. Kudryashov, P. Mayer-Kuckuk, R. Roy, and I. Binderman, "Modulation of extracellular matrix protein phosphorylation alters mineralization in differentiating chick limb-bud mesenchymal cell micromass cultures," Bone, vol. 42, no. 6, pp. 1061-1071, 2008.

[61] W. N. Addison, F. Azari, E. S. Sørensen, M. T. Kaartinen, and M. D. McKee, "Pyrophosphate inhibits mineralization of osteoblast cultures by binding to mineral, up-regulating osteopontin, and inhibiting alkaline phosphatase activity," Journal of Biological Chemistry, vol. 282, no. 21, pp. 15872-15883, 2007.

[62] W. Jahnen-Dechent, C. Schäfer, M. Ketteler, and M. D. McKee, "Mineral chaperones: a role for fetuin-A and osteopontin in the inhibition and regression of pathologic calcification," Journal of Molecular Medicine, vol. 86, no. 4, pp. 379-389, 2008.

[63] A. Gericke, C. Qin, L. Spevak et al., "Importance of phosphorylation for osteopontin regulation of biomineralization," Calcified Tissue International, vol. 77, no. 1, pp. 45-54, 2005.

[64] A. L. Boskey, L. Spevak, E. Paschalis, S. B. Doty, and M. D. McKee, "Osteopontin deficiency increases mineral content and mineral crystallinity in mouse bone," Calcified Tissue International, vol. 71, no. 2, pp. 145-154, 2002.
[65] Y. Matsui, S. R. Rittling, H. Okamoto et al., "Osteopontin deficiency attenuates atherosclerosis in female apolipoprotein E-deficient mice," Arteriosclerosis, Thrombosis, and Vascular Biology, vol. 23, no. 6, pp. 1029-1034, 2003.

[66] J. A. Wesson, R. J. Johnson, M. Mazzali et al., "Osteopontin is a critical inhibitor of calcium oxalate crystal formation and retention in renal tubules," Journal of the American Society of Nephrology, vol. 14, no. 1, pp. 139-147, 2003.

[67] A. L. Boskey, B. Christensen, H. Taleb, and E. S. Sørensen, "Post-translational modification of osteopontin: effects on in vitro hydroxyapatite formation and growth," Biochemical and Biophysical Research Communications, vol. 419, no. 2, pp. 333338, 2012.

[68] T. Nagata, R. Todescan, H. A. Goldberg, Q. Zhang, and J. Sodek, "Sulphation of secreted phosphoprotein I (SPPI, osteopontin) is associated with mineralized tissue formation," Biochemical and Biophysical Research Communications, vol. 165, no. 1, pp. 234240, 1989.

[69] R. Zohar, W. Lee, P. Arora, S. Cheifetz, C. McCulloch, and J. Sodek, "Single cell analysis of intracellular osteopontin in osteogenic cultures of fetal rat calvarial cells," Journal of Cellular Physiology, vol. 170, no. 1, pp. 88-100, 1997.

[70] A. Junaid, M. C. Moon, G. E. J. Harding, and P. Zahradka, "Osteopontin localizes to the nucleus of 293 cells and associates with polo-like kinase-1," American Journal of Physiology-Cell Physiology, vol. 292, no. 2, pp. C919-C926, 2007.

[71] H. Cantor and M. L. Shinohara, "Regulation of T-helper-cell lineage development by osteopontin: the inside story," Nature Reviews Immunology, vol. 9, no. 2, pp. 137-141, 2009.

[72] M. L. Shinohara, M. Jansson, E. S. Hwang, M. B. F. Werneck, L. H. Glimcher, and H. Cantor, "T-bet-dependent expression of osteopontin contributes to T cell polarization," Proceedings of the National Academy of Sciences of the United States of America, vol. 102, no. 47, pp. 17101-17106, 2005.

[73] J. W. Leavenworth, B. Verbinnen, J. Yin, H. Huang, and H. Cantor, "A p85 $\alpha$-osteopontin axis couples the receptor ICOS to sustained Bcl-6 expression by follicular helper and regulatory $\mathrm{T}$ cells," Nature Immunology, vol. 16, no. 1, pp. 96-106, 2015.

[74] R. Zohar, N. Suzuki, K. Suzuki et al., "Intracellular osteopontin is an integral component of the CD44-ERM complex involved in cell migration," Journal of Cellular Physiology, vol. 184, no. 1, pp. 118-130, 2000.

[75] B. Zhu, K. Suzuki, H. A. Goldberg et al., "Osteopontin modulates CD44-dependent chemotaxis of peritoneal macrophages through G-protein-coupled receptors: evidence of a role for an intracellular form of osteopontin," Journal of Cellular Physiology, vol. 198, no. 1, pp. 155-167, 2004.

[76] K. Suzuki, S. Takeyama, Y. Sakai, S. Yamada, and H. Shinoda, "Current topics in pharmacological research on bone metabolism: inhibitory effects of bisphosphonates on the differentiation and activity of osteoclasts," Journal of Pharmacological Sciences, vol. 100, no. 3, pp. 189-194, 2006.

[77] K. Masutani, M. Akahoshi, K. Tsuruya et al., "Predominance of Thl immune response in diffuse proliferative lupus nephritis," Arthritis and Rheumatism, vol. 44, no. 9, pp. 2097-2106, 2001 (Lithuanian).

[78] Y. Katagiri, K. Mori, T. Hara, K. Tanaka, M. Murakami, and T. Uede, "Functional analysis of the osteopontin molecule," Annals of the New York Academy of Sciences, vol. 760, pp. 371-374, 1995.

[79] D. Chabas, S. E. Baranzini, D. Mitchell et al., "The influence of the proinflammatory cytokine, osteopontin, on autoimmune 
demyelinating disease," Science, vol. 294, no. 5547, pp. 1731-1735, 2001.

[80] S. Ohsima, N. Yamaguchi, K. Nishioka et al., "Enhanced local production of osteopontin in rheumatoid joints," Journal of Rheumatology, vol. 29, pp. 2061-2067, 2002.

[81] R. Mishima, F. Takeshima, T. Sawai et al., "High plasma osteopontin levels in patients with inflammatory bowel disease," Journal of Clinical Gastroenterology, vol. 41, no. 2, pp. 167-172, 2007.

[82] J. Iizuka, Y. Katagiri, N. Tada et al., "Introduction of an osteopontin gene confers the increase in B1 cell population and the production of anti-DNA autoantibodies," Laboratory Investigation, vol. 78, no. 12, pp. 1523-1533, 1998.

[83] M. Braitch and C. S. Constantinescu, "The role of osteopontin in experimental autoimmune encephalomyelitis (EAE) and multiple sclerosis (MS)," Inflammation and Allergy -Drug Targets, vol. 9, no. 4, pp. 249-256, 2010.

[84] K. Yumoto, M. Ishijima, S. R. Rittling et al., "Osteopontin deficiency protects joints against destruction in anti-type II collagen antibody-induced arthritis in mice," Proceedings of the National Academy of Sciences of the United States of America, vol. 99, no. 7, pp. 4556-4561, 2002.

[85] T. Nomiyama, D. Perez-Tilve, D. Ogawa et al., "Osteopontin mediates obesity-induced adipose tissue macrophage infiltration and insulin resistance in mice," Journal of Clinical Investigation, vol. 117, no. 10, pp. 2877-2888, 2007.

[86] M. Kitamura, K. Iwabuchi, N. Kitaichi et al., "Osteopontin aggravates experimental autoimmune uveoretinitis in mice," Journal of Immunology, vol. 178, no. 10, pp. 6567-6572, 2007.

[87] W.-K. Syn, S. S. Choi, E. Liaskou et al., "Osteopontin is induced by hedgehog pathway activation and promotes fibrosis progression in nonalcoholic steatohepatitis," Hepatology, vol. 53, no. 1, pp. 106-115, 2011.

[88] O. Morales-Ibanez, M. Domínguez, S. H. Ki et al., "Human and experimental evidence supporting a role for osteopontin in alcoholic hepatitis," Hepatology, vol. 58, no. 5, pp. 1742-1756, 2013.

[89] K. Heilmann, U. Hoffmann, E. Witte et al., "Osteopontin as twosided mediator of intestinal inflammation," Journal of Cellular and Molecular Medicine, vol. 13, no. 6, pp. 1162-1174, 2009.

[90] S. Husain-Krautter, J. M. Kramer, W. Li, B. Guo, and T. L. Rothstein, "The osteopontin transgenic mouse is a new model for Sjögren's syndrome," Clinical Immunology, vol. 157, no. 1, pp. 30-42, 2015.

[91] D. F. Frenzel, L. Borkner, J. Scheurmann, K. Singh, K. Scharffetter-Kochanek, and J. M. Weiss, "Osteopontin deficiency affects imiquimod-induced psoriasis-like murine skin inflammation and lymphocyte distribution in skin, draining lymph nodes and spleen," Experimental Dermatology, vol. 24, no. 4, pp. 305-307, 2015.

[92] J. Bentham, D. L. Morris, D. S. Cunninghame Graham et al., "Genetic association analyses implicate aberrant regulation of innate and adaptive immunity genes in the pathogenesis of systemic lupus erythematosus," Nature Genetics, vol. 47, no. 12, pp. 1457-1464, 2015.

[93] E. A. Stahl, S. Raychaudhuri, E. F. Remmers et al., "Genomewide association study meta-analysis identifies seven new rheumatoid arthritis risk loci," Nature Genetics, vol. 42, no. 6 , pp. 508-514, 2010.

[94] C. Cotsapas, B. F. Voight, E. Rossin et al., "Pervasive sharing of genetic effects in autoimmune disease," PLoS Genetics, vol. 7, no. 8, Article ID e1002254, 2011.
[95] S. Alfadhli, A. A. M. Ghanem, and R. Nizam, "Genome-wide differential expression reveals candidate genes involved in the pathogenesis of lupus and lupus nephritis," International Journal of Rheumatic Diseases, vol. 19, no. 1, pp. 55-64, 2016.

[96] X.-F. Pan, J.-Q. Gu, and Z.-Y. Shan, "Patients with systemic lupus erythematosus have higher prevalence of thyroid autoantibodies: a systematic review and meta-analysis," PLOS ONE, vol. 10, no. 4, Article ID e0123291, 2015.

[97] S. Iwata and Y. Tanaka, "B-cell subsets, signaling and their roles in secretion of autoantibodies," Lupus, vol. 25, no. 8, pp. 850856, 2016.

[98] R. Patarca, F.-Y. Wei, P. Singh, M. I. Morasso, and H. Cantor, "Dysregulated expression of the T cell cytokine Eta-1 in CD4-8lymphocytes during the development of murine autoimmune disease," Journal of Experimental Medicine, vol. 172, no. 4, pp. 1177-1183, 1990.

[99] A. N. Theofilopoulos and F. J. Dixon, "Etiopathogenesis of murine SLE," Immunological Reviews, vol. 55, pp. 179-216, 1981.

[100] P. L. Cohen and R. A. Eisenberg, "Lpr and gld: single gene models of systemic autoimmunity and lymphoproliferative disease," Annual Review of Immunology, vol. 9, no. 1, pp. 243269, 1991.

[101] G. F. Weber and H. Cantor, "Differential roles of osteopontin/ Eta-1 in early and late lpr disease," Clinical and Experimental Immunology, vol. 126, no. 3, pp. 578-583, 2001.

[102] M. Aricò, E. Boggio, V. Cetica et al., "Variations of the UNC13D gene in patients with autoimmune lymphoproliferative syndrome," PLoS ONE, vol. 8, no. 7, Article ID e68045, 2013.

[103] R. Clementi, A. Chiocchetti, G. Cappellano et al., "Variations of the perforin gene in patients with autoimmunity/lymphoproliferation and defective Fas function," Blood, vol. 108, no. 9, pp. 3079-3084, 2006.

[104] M. Ono, T. Yamamoto, and M. Nose, "Allelic difference in the nucleotide sequence of the Eta-1/Op gene transcript," Molecular Immunology, vol. 32, no. 6, pp. 447-448, 1995.

[105] E. Boggio, M. Indelicato, E. Orilieri et al., "Role of tissue inhibitor of metalloproteinases-1 in the development of autoimmune lymphoproliferation," Haematologica, vol. 95, no. 11, pp. 1897-1904, 2010.

[106] E. Boggio, N. Clemente, A. Mondino et al., "IL-17 protects T cells from apoptosis and contributes to development of ALPSlike phenotypes," Blood, vol. 123, no. 8, pp. 1178-1186, 2014.

[107] C. K. Wong, L. C. W. Lit, L. S. Tam, E. K. Li, and C. W. $\mathrm{K}$. Lam, "Elevation of plasma osteopontin concentration is correlated with disease activity in patients with systemic lupus erythematosus," Rheumatology, vol. 44, no. 5, pp. 602-606, 2005.

[108] O. J. Rullo, J. M. P. Woo, M. F. Parsa et al., "Plasma levels of osteopontin identify patients at risk for organ damage in systemic lupus erythematosus," Arthritis Research \& Therapy, vol. 15, no. 1, article R18, 2013.

[109] K. Masutani, M. Akahoshi, K. Tsuruya et al., "Predominance of Th1 immune response in diffuse proliferative lupus nephritis," Arthritis \& Rheumatism, vol. 44, no. 9, pp. 2097-2106, 2001.

[110] M. Quaglia, A. Chiocchetti, T. Cena et al., "Osteopontin circulating levels correlate with renal involvement in systemic lupus erythematosus and are lower in ACE inhibitor-treated patients," Clinical Rheumatology, vol. 33, no. 9, pp. 1263-1271, 2014.

[111] S. N. Kariuki, J. G. Moore, K. A. Kirou, M. K. Crow, T. O. Utset, and T. B. Niewold, "Age- and gender-specific modulation of 
serum osteopontin and interferon- $\alpha$ by osteopontin genotype in systemic lupus erythematosus," Genes \& Immunity, vol. 10, no. 5, pp. 487-494, 2009.

[112] Y. Tanino, N. Hizawa, S. Konno et al., "Sequence variants of the secreted phosphoprotein 1 gene are associated with total serum immunoglobulin E levels in a Japanese population," Clinical \& Experimental Allergy, vol. 36, no. 2, pp. 219-225, 2006.

[113] S. Han, J. M. Guthridge, I. T. W. Harley et al., "Osteopontin and Systemic Lupus Erythematous association: a probable gene-gender interaction," PLOS ONE, vol. 3, no. 3, Article ID e0001757, 2008.

[114] D. T. Denhardt, M. Noda, A. W. O’Regan, D. Pavlin, and J. S. Berman, "Osteopontin as a means to cope with environmental insults: regulation of inflammation, tissue remodeling, and cell survival," Journal of Clinical Investigation, vol. 107, no. 9, pp. 1055-1061, 2001.

[115] S. Salimi, M. Noora, S. Nabizadeh et al., "Association of the osteopontin rs1126616 polymorphism and a higher serum osteopontin level with lupus nephritis," Biomedical Reports, vol. 4, no. 3, pp. 355-360, 2016.

[116] J. Merszei, J. Wu, L. Torres et al., "Osteopontin overproduction is associated with progression of glomerular fibrosis in a rat model of anti-glomerular basement membrane glomerulonephritis," American Journal of Nephrology, vol. 32, no. 3, pp. 262-271, 2010.

[117] C. Zhou, J. Wu, L. Torres et al., "Blockade of osteopontin inhibits glomerular fibrosis in a model of anti-glomerular basement membrane glomerulonephritis," American Journal of Nephrology, vol. 32, no. 4, pp. 324-331, 2010.

[118] T. Wolak, H. Kim, Y. Ren, J. Kim, N. D. Vaziri, and S. B. Nicholas, "Osteopontin modulates angiotensin II-induced inflammation, oxidative stress, and fibrosis of the kidney," Kidney International, vol. 76, no. 1, pp. 32-43, 2009.

[119] C. M. Giachelli, L. Liaw, C. E. Murry, S. M. Schwartz, and M. Almeida, "Osteopontin expression in cardiovascular diseases," Annals of the New York Academy of Sciences, vol. 760, pp. 109126, 1995.

[120] D. Bruemmer, A. R. Collins, G. Noh et al., "Angiotensin IIaccelerated atherosclerosis and aneurysm formation is attenuated in osteopontin-deficient mice," The Journal of Clinical Investigation, vol. 112, no. 9, pp. 1318-1331, 2003.

[121] B. G. Weinshenker, "The natural history of multiple sclerosis," Neurologic Clinics, vol. 13, no. 1, pp. 119-146, 1995.

[122] S. A. Lund, C. M. Giachelli, and M. Scatena, "The role of osteopontin in inflammatory processes," Journal of Cell Communication and Signaling, vol. 3, no. 3-4, pp. 311-322, 2009.

[123] M. H. J. Vogt, L. Lopatinskaya, M. Smits, C. H. Polman, and L. Nagelkerken, "Elevated osteopontin levels in active relapsingremitting multiple sclerosis," Annals of Neurology, vol. 53, no. 6, pp. 819-822, 2003.

[124] C. Sinclair, M. Mirakhur, J. Kirkt, M. Farrell, and S. McQuaid, "Up-regulation of osteopontin and $\alpha \beta$-crystallin in the normalappearing white matter of multiple sclerosis: an immunohistochemical study utilizing tissue microarrays," Neuropathology and Applied Neurobiology, vol. 31, no. 3, pp. 292-303, 2005.

[125] M. Comabella, I. Pericot, R. Goertsches et al., "Plasma osteopontin levels in multiple sclerosis," Journal of Neuroimmunology, vol. 158, no. 1-2, pp. 231-239, 2005.

[126] L. Börnsen, M. Khademi, T. Olsson, P. S. Sørensen, and F. Sellebjerg, "Osteopontin concentrations are increased in cerebrospinal fluid during attacks of multiple sclerosis," Multiple Sclerosis Journal, vol. 17, no. 1, pp. 32-42, 2011.
[127] M. Carecchio and C. Comi, "The role of osteopontin in neurodegenerative diseases," Journal of Alzheimer's Disease, vol. 25, no. 2, pp. 179-185, 2011.

[128] E. M. Hur, S. Youssef, M. E. Haws, S. Y. Zhang, R. A. Sobel, and L. Steinman, "Osteopontin-induced relapse and progression of autoimmune brain disease through enhanced survival of activated T cells," Nature Immunology, vol. 8, no. 1, pp. 74-83, 2007.

[129] R. K. Han, Y. F. Cheng, S. S. Zhou et al., "Increased circulating Th17 cell populations and elevated CSF osteopontin and il17 concentrations in patients with Guillain-Barré syndrome," Journal of Clinical Immunology, vol. 34, no. 1, pp. 94-103, 2014.

[130] M. Chen, G. Chen, H. Nie et al., "Regulatory effects of IFN- $\beta$ on production of osteopontin and IL-17 by CD $4^{+}$T Cells in MS," European Journal of Immunology, vol. 39, no. 9, pp. 2525-2536, 2009.

[131] S. Cailier, L. F. Baranzini, A. Swerdlin et al., "Multiple Sclerosis Genetics Group. Osteopontin polymorphisms and disease course in multiple sclerosis," Genes and Immunity, vol. 4, no. 4, pp. 312-315, 2003.

[132] A. Chiocchetti, C. Comi, M. Indelicato et al., "Osteopontin gene haplotypes correlate with multiple sclerosis development and progression," Journal of Neuroimmunology, vol. 163, no. 1-2, pp. 172-178, 2005.

[133] M. Jansson, V. Panoutsakopoulou, J. Baker, L. Klein, and H. Cantor, "Cutting edge: attenuated experimental autoimmune encephalomyelitis in Eta-1/osteopontin-deficient mice," Journal of Immunology, vol. 168, no. 5, pp. 2096-2099, 2002.

[134] H. Neumann, I. M. Medana, J. Bauer, and H. Lassmann, "Cytotoxic T lymphocytes in autoimmune and degenerative CNS diseases," Trends in Neurosciences, vol. 25, no. 6, pp. 313319, 2002.

[135] L. Steinman, "Blocking adhesion molecules as therapy for multiple sclerosis: natalizumab," Nature Reviews Drug Discovery, vol. 4, no. 6, pp. 510-518, 2005.

[136] L. Steinman, "Some misconceptions about understanding autoimmunity through experiments with knockouts," Journal of Experimental Medicine, vol. 185, no. 12, pp. 2039-2041, 1997.

[137] A. O’Regan and J. S. Berman, "Osteopontin: a key cytokine in cell-mediated and granulomatous inflammation," International Journal of Experimental Pathology, vol. 81, no. 6, pp. 373-390, 2000.

[138] M. Hashimoto, D. Sun, S. R. Rittling, D. T. Denhardt, and W. Young, "Osteopontin-deficient mice exhibit less inflammation, greater tissue damage, and impaired locomotor recovery from spinal cord injury compared with wild-type controls," Journal of Neuroscience, vol. 27, no. 13, pp. 3603-3611, 2007.

[139] R. Selvaraju, L. Bernasconi, C. Losberger et al., "Osteopontin is upregulated during in vivo demyelination and remyelination and enhances myelin formation in vitro," Molecular and Cellular Neuroscience, vol. 25, no. 4, pp. 707-721, 2004.

[140] M. Rabenstein, J. Hucklenbroich, A. Willuweit et al., "Osteopontin mediates survival, proliferation and migration of neural stem cells through the chemokine receptor CXCR4," Stem Cell Research \& Therapy, vol. 6, article 99, 2015.

[141] M. D. McKee and A. Nanci, "Osteopontin at mineralized tissue interfaces in bone, teeth, and osseointegrated implants: ultrastructural distribution and implications for mineralized tissue formation, turnover, and repair," Microscopy Research and Technique, vol. 33, no. 2, pp. 141-164, 1996. 
[142] M. G. Attur, M. N. Dave, S. Stuchin et al., "Osteopontin: an intrinsic inhibitor of inflammation in cartilage," Arthritis and Rheumatism, vol. 44, no. 3, pp. 578-584, 2001.

[143] F. Zhang, W. Luo, Y. Li, S. Gao, and G. Lei, "Role of osteopontin in rheumatoid arthritis," Rheumatology International, vol. 35, no. 4, pp. 589-595, 2015.

[144] S. G. Gao, K. H. Li, K. B. Zeng, M. Tu, M. Xu, and G. H. Lei, "Elevated osteopontin level of synovial fluid and articular cartilage is associated with disease severity in knee osteoarthritis patients," Osteoarthritis and Cartilage, vol. 18, no. 1, pp. 82-87, 2010.

[145] K. Suzuki, B. Zhu, S. R. Rittling et al., "Colocalization of intracellular osteopontin with CD44 is associated with migration, cell fusion, and resorption in osteoclasts," Journal of Bone and Mineral Research, vol. 17, no. 8, pp. 1486-1497, 2002.

[146] S. Ohshima, H. Kobayashi, N. Yamaguchi et al., "Expression of osteopontin at sites of bone erosion in a murine experimental arthritis model of collagen-induced arthritis: possible involvement of osteopontin in bone destruction in arthritis," Arthritis \& Rheumatism, vol. 46, no. 4, pp. 1094-1101, 2002.

[147] A. M. Badger, S. Blake, R. Kapadia et al., "Disease-modifying activity of SB 273005, an orally active, nonpeptide $\alpha \mathrm{v} \beta 3$ (vitronectin receptor) antagonist, in rat adjuvant-induced arthritis," Arthritis and Rheumatism, vol. 44, no. 1, pp. 128-137, 2001.

[148] N. Yamamoto, F. Sakai, S. Kon et al., "Essential role of the cryptic epitope SLAYGLR within osteopontin in a murine model of rheumatoid arthritis," The Journal of Clinical Investigation, vol. 112, no. 2, pp. 181-188, 2003.

[149] M. Yamaga, K. Tsuji, K. Miyatake et al., "Osteopontin level in synovial fluid is associated with the severity of joint pain and cartilage degradation after anterior cruciate ligament rupture," PLoS ONE, vol. 7, no. 11, Article ID e49014, 2012.

[150] S. A. Sharif, X. Du, T. Myles et al., "Thrombin-activatable carboxypeptidase B cleavage of osteopontin regulates neutrophil survival and synoviocyte binding in rheumatoid arthritis," Arthritis and Rheumatism, vol. 60, no. 10, pp. 2902-2912, 2009.

[151] Y. Take, K. Nakata, J. Hashimoto et al., "Specifically modified osteopontin in rheumatoid arthritis fibroblast-like synoviocytes supports interaction with B cells and enhances production of interleukin-6," Arthritis \& Rheumatism, vol. 60, no. 12, pp. 35913601, 2009.

[152] G. Chen, X. Zhang, R. Li et al., "Role of osteopontin in synovial Th17 differentiation in rheumatoid arthritis," Arthritis and Rheumatism, vol. 62, no. 10, pp. 2900-2908, 2010.

[153] E. Urcelay, A. Martínez, A. Mas-Fontao et al., "Osteopontin gene polymorphisms in spanish patients with rheumatoid arthritis," The Journal of Rheumatology, vol. 32, no. 3, pp. 405-409, 2005.

[154] G. Xu, W. Sun, D. He et al., "Overexpression of osteopontin in rheumatoid synovial mononuclear cells is associated with joint inflammation, not with genetic polymorphism," The Journal of Rheumatology, vol. 32, no. 3, pp. 410-416, 2005.

[155] F. Ceccarelli, S. D’Alfonso, C. Perricone et al., "The role of eight polymorphisms in three candidate genes in determining the susceptibility, phenotype, and response to anti-TNF therapy in patients with rheumatoid arthritis," Clinical and Experimental Rheumatology, vol. 30, no. 6, pp. 939-942, 2012.

[156] K. Izumi, Y. Kaneko, M. Hashizume, K. Yoshimoto, and T. Takeuchi, "Baseline serum osteopontin levels predict the clinical effectiveness of tocilizumab but not infliximab in biologic-Naïve patients with rheumatoid arthritis: a singlecenter prospective study at 1 year (the Keio First-Bio Cohort study)," PLOS ONE, vol. 10, no. 12, Article ID e0145468, 2015.
[157] C. Cheng, S. Gao, and G. Lei, "Association of osteopontin with osteoarthritis," Rheumatology International, vol. 34, no. 12, pp. 1627-1632, 2014.

[158] S. Honsawek, A. Tanavalee, M. Sakdinakiattikoon, M. Chayanupatkul, and P. Yuktanandana, "Correlation of plasma and synovial fluid osteopontin with disease severity in knee osteoarthritis," Clinical Biochemistry, vol. 42, no. 9, pp. 808-812, 2009.

[159] T. M. Griffin and F. Guilak, "The role of mechanical loading in the onset and progression of osteoarthritis," Exercise and Sport Sciences Reviews, vol. 33, no. 4, pp. 195-200, 2005.

[160] F.-J. Zhang, W.-B. Yu, W. Luo, S.-G. Gao, Y.-S. Li, and G.-H. Lei, "Effect of osteopontin on TIMP-1 and TIMP-2 mRNA in chondrocytes of human knee osteoarthritis in vitro," Experimental and Therapeutic Medicine, vol. 8, no. 2, pp. 391-394, 2014.

[161] R. C. Billinghurst, L. Dahlberg, M. Ionescu et al., "Enhanced cleavage of type II collagen by collagenases in osteoarthritic articular cartilage," The Journal of Clinical Investigation, vol. 99, no. 7, pp. 1534-1545, 1997.

[162] M. G. Attur, I. R. Patel, R. N. Patel, S. B. Abramson, and A. R. Amin, "Autocrine production of IL-1 $\beta$ by human osteoarthritisaffected cartilage and differential regulation of endogenous nitric oxide, IL-6, prostaglandin E2, and IL-8," Proceedings of the Association of American Physicians, vol. 110, no. 1, pp. 65-72, 1998.

[163] D. Daneman, “Type 1 diabetes," The Lancet, vol. 367, no. 9513, pp. 847-858, 2006.

[164] I. Barchetta, C. Alessandri, L. Bertoccini et al., "Increased circulating osteopontin levels in adult patients with type 1 diabetes mellitus and association with dysmetabolic profile," European Journal of Endocrinology, vol. 174, no. 2, pp. 187-192, 2016.

[165] M. Talat, L. Sherief, H. El-Saadany, A. Ahmed, R. Salah, and M. sakr, "The role of osteopontin in the pathogenesis and complication of type 1 diabetes mellitus in children and adolescents," Journal of Clinical Research in Pediatric Endocrinology, 2016.

[166] D. Gordin, C. Forsblom, N. M. Panduru et al., "Osteopontin is a strong predictor of incipient diabetic nephropathy, cardiovascular disease, and all-cause mortality in patients with type 1 diabetes," Diabetes Care, vol. 37, no. 9, pp. 2593-2600, 2014.

[167] A. Fierabracci, P. A. Biro, Y. Yiangou et al., "Osteopontin is an autoantigen of the somatostatin cells in human islets: identification by screening random peptide libraries with sera of patients with insulin-dependent diabetes mellitus," Vaccine, vol. 18, no. 3-4, pp. 342-354, 1999.

[168] Y. H. Wang, M. S. Zhao, and Y. Zhao, "Expression of osteopontin in labial glands of patients with primary Sjögren's syndrome," Beijing Da Xue Xue Bao, vol. 44, no. 2, pp. 236-239, 2012.

[169] G.-L. Wu, N.-Y. Wu, T.-Y. Li, Y.-S. Fan, G.-Y. Yu, and W.W. Lu, "Effect of Chinese herbal medicines for nourishing yin, supplementing qi, and activating blood on reproductive endocrine activity and immune functions in patients with primary Sjogren's syndrome," Chinese Journal of Integrative Medicine, vol. 21, no. 10, pp. 778-783, 2015.

[170] S. Cha, A. B. Peck, and M. G. Humphreys-Beher, "Progress in understanding autoimmune exocrinopathy using the nonobese diabetic mouse: an update," Critical Reviews in Oral Biology and Medicine, vol. 13, no. 1, pp. 5-16, 2002.

[171] N. Gassler, F. Autschbach, S. Gauer et al., "Expression of osteopontin (Eta-1) in Crohn disease of the terminal ileum," Scandinavian Journal of Gastroenterology, vol. 37, no. 11, pp. 1286-1295, 2002.

[172] J. Agnholt, J. Kelsen, L. Schack, C. L. Hvas, J. F. Dahlerup, and E. S. Sørensen, "Osteopontin, a protein with cytokine-like 
properties, is associated with inflammation in Crohn's disease," Scandinavian Journal of Immunology, vol. 65, no. 5, pp. 453-460, 2007.

[173] J. N. Gordon and T. T. MacDonald, "Osteopontin: a new addition to the constellation of cytokines which drive T helper cell type 1 responses in Crohn's disease," Gut, vol. 54, no. 9, pp. 1213-1215, 2005.

[174] T. Sato, T. Nakai, N. Tamura et al., "Osteopontin/Eta-1 upregulated in Crohn's disease regulates the Thl immune response," Gut, vol. 54, no. 9, pp. 1254-1262, 2005.

[175] S. Komine-Aizawa, H. Masuda, T. Mazaki, M. Shiono, S. Hayakawa, and T. Takayama, "Plasma osteopontin predicts inflammatory bowel disease activities," International Surgery, vol. 100, no. 1, pp. 38-43, 2015.

[176] K. Heilmann, U. Hoffmann, E. Witte et al., "Osteopontin as twosided mediator of intestinal inflammation," Journal of Cellular and Molecular Medicine, vol. 13, no. 6, pp. 1162-1174, 2009.

[177] M. Sakata, J.-I. Tsuruha, K. Masuko-Hongo et al., "Autoantibodies to osteopontin in patients with osteoarthritis and rheumatoid arthritis," Journal of Rheumatology, vol. 28, no. 7, pp. 1492-1495, 2001.

[178] G. Cappellano, E. Orilieri, A. D. Woldetsadik et al., "Anticytokineautoantibodies in autoimmune diseases," American Journal of Clinical and Experimental Immunology, vol. 1, no. 2, pp. 136-146, 2012.

[179] L. Steinman, S. Youssef, N. Van Venrooij et al., "Response to Comment on 'The influence of the proinflammatory cytokine, osteopontin, on autoimmune demyelinating disease," Science, vol. 299, article 1845, 2003.

[180] M. J. H. Boumans, J. G. A. Houbiers, P. Verschueren et al., "Safety, tolerability, pharmacokinetics, pharmacodynamics and efficacy of the monoclonal antibody ASK8007 blocking osteopontin in patients with rheumatoid arthritis: a randomised, placebo controlled, proof-of-concept study," Annals of the Rheumatic Diseases, vol. 71, no. 2, pp. 180-185, 2012.

[181] S. Kon, Y. Yokosaki, M. Maeda et al., "Mapping of functional epitopes of osteopontin by monoclonal antibodies raised against defined internal sequences," Journal of Cellular Biochemistry, vol. 84, no. 2, pp. 420-432, 2002.

[182] C.-M. Su, Y.-C. Chiang, C.-Y. Huang, C.-J. Hsu, Y.-C. Fong, and C.-H. Tang, "Osteopontin promotes oncostatin M production in human osteoblasts: implication of rheumatoid arthritis therapy," The Journal of Immunology, vol. 195, no. 7, pp. 3355-3364, 2015.

[183] D. Iwata, M. Kitamura, N. Kitaichi et al., "Prevention of experimental autoimmune uveoretinitis by blockade of osteopontin with small interfering RNA," Experimental Eye Research, vol. 90, no. 1, pp. 41-48, 2010. 


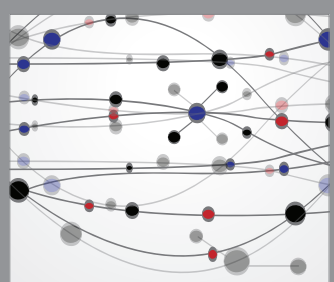

The Scientific World Journal
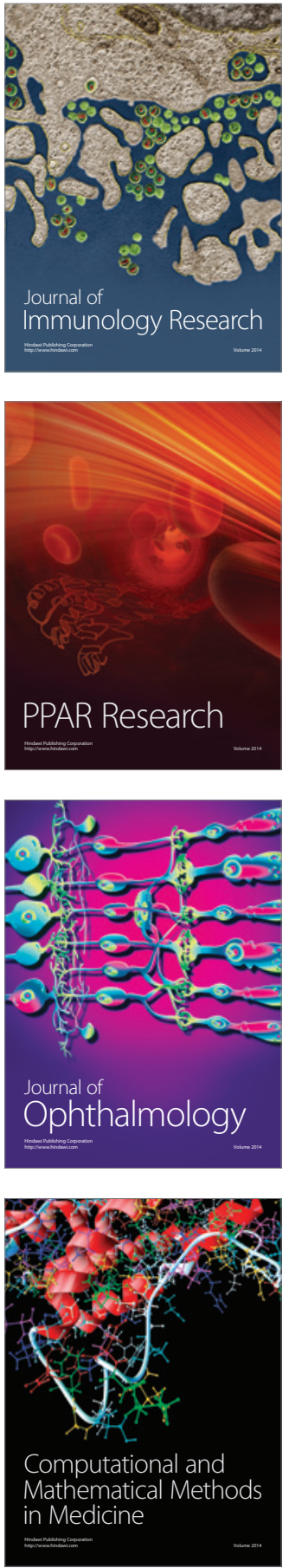

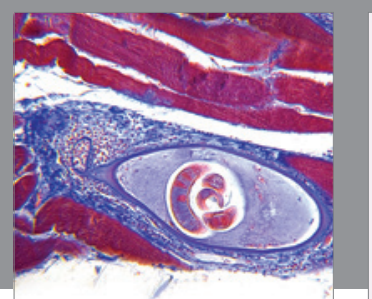

Gastroenterology Research and Practice

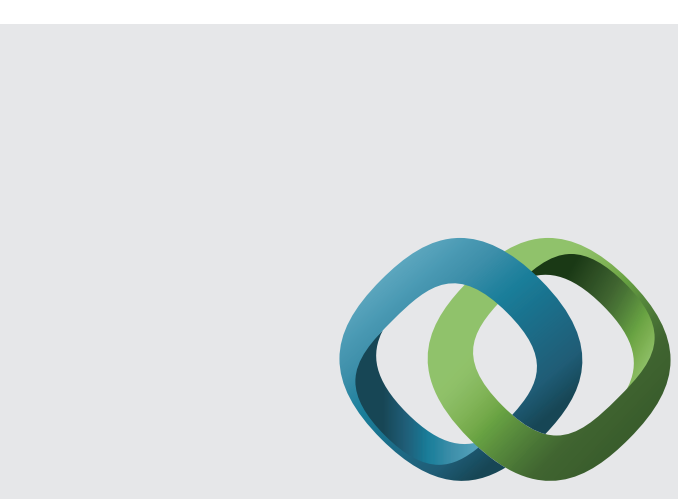

\section{Hindawi}

Submit your manuscripts at

http://www.hindawi.com
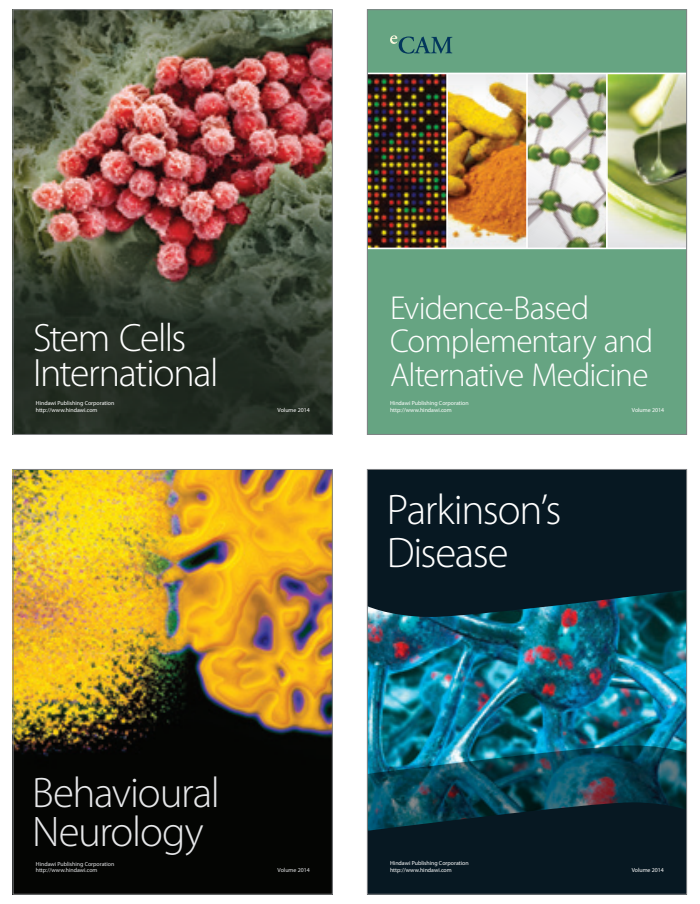
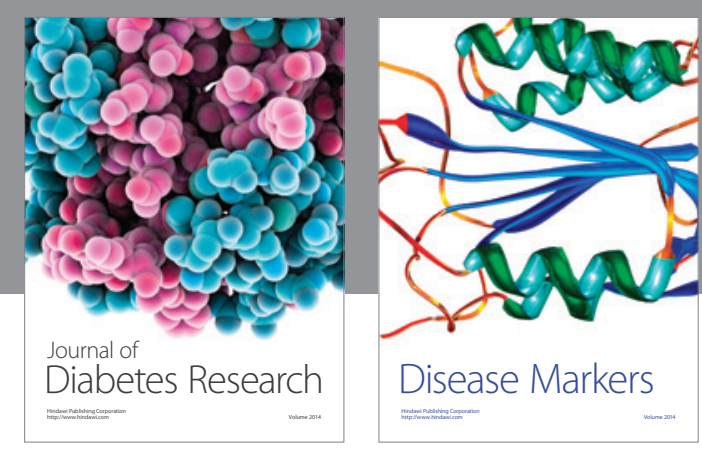

Disease Markers
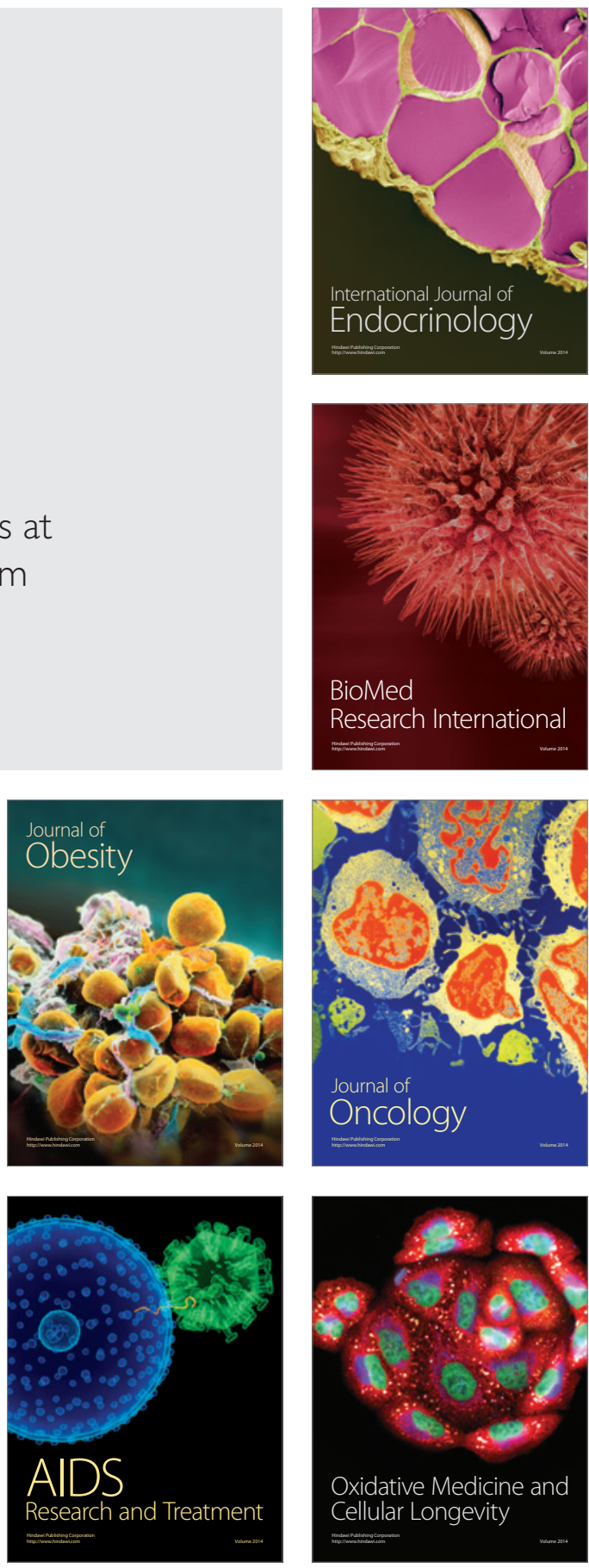